\title{
The New Economic Case for Migration Restrictions: An Assessment
}

\author{
Michael Clemens and Lant Pritchett \\ CID Working Paper No. 314 \\ February 2016
}

(c) Copyright 2016 Clemens, Michael; Pritchett, Lant; and the President and Fellows of Harvard College

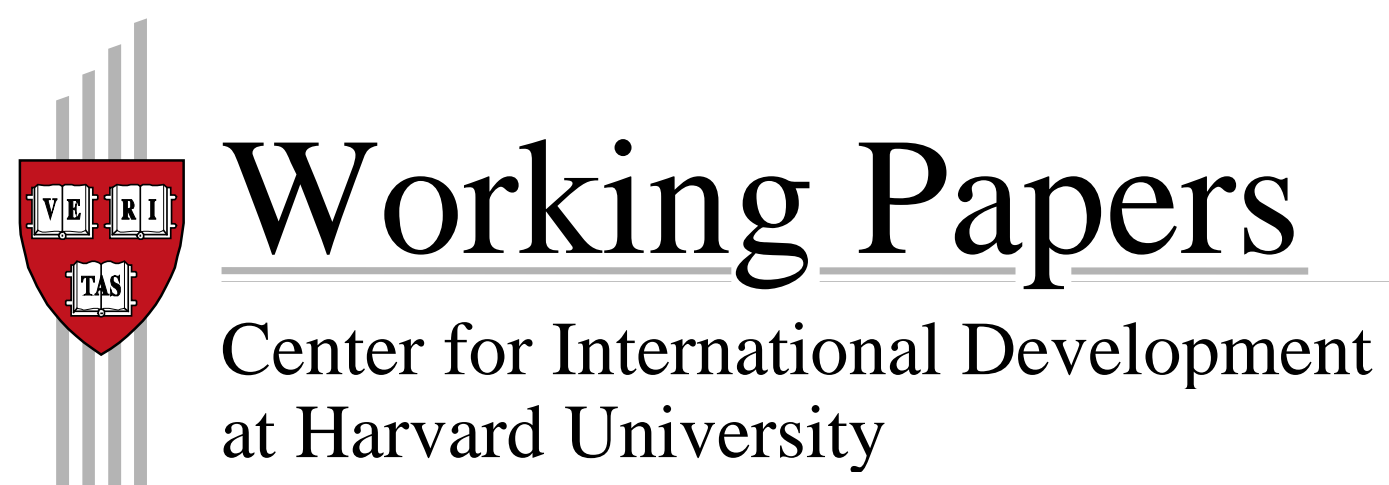




\title{
The New Economic Case for Migration Restrictions: An Assessment
}

\author{
Michael A. Clemens* \\ Center for Global \\ Development and IZA
}

\author{
Lant Pritchett
}

Harvard Kennedy School and

Center for Global Development

February 2016

\begin{abstract}
For decades, migration economics has stressed the effects of migration restrictions on income distribution in the host country. Recently the literature has taken a new direction by estimating the costs of migration restrictions to global economic efficiency. In contrast, a new strand of research posits that migration restrictions could be not only desirably redistributive, but in fact globally efficient. This is the new economic case for migration restrictions. The case rests on the possibility that without tight restrictions on migration, migrants from poor countries could transmit low productivity (" $A$ " or Total Factor Productivity) to rich countries - offsetting efficiency gains from the spatial reallocation of labor from low to high-productivity places. We provide a novel assessment, proposing a simple model of dynamically efficient migration under productivity transmission and calibrating it with new macro and micro data. In this model, the case for efficiency-enhancing migration barriers rests on three parameters: transmission, the degree to which origin-country total factor productivity is embodied in migrants; assimilation, the degree to which migrants' productivity determinants become like natives' over time in the host country; and congestion, the degree to which transmission and assimilation change at higher migrant stocks. On current evidence about the magnitudes of these parameters, dynamically efficient policy would not imply open borders but would imply relaxations on current restrictions. That is, the new efficiency case for some migration restrictions is empirically a case against the stringency of current restrictions.
\end{abstract}

*JEL Codes F22, J61, O11. Center for Global Development, 2055 L Street NW, Washington, DC 20036 USA, mclemens@cgdev.org. We gratefully acknowledge support from Good Ventures, the Development Research Institute at New York University, and the John Templeton Foundation. We thank Hannah Postel for excellent research assistance. We thank Thorsten Beck, Arnaud Chevalier, Matt Collin, Diego Daruich, Bill Easterly, Ben Elsner, Corrado Giuletti, Chad Jones, Devesh Kapur, Bob Lawson, Henry Ma, Elie Murard, Dani Rodrik, Justin Sandefur, Massimiliano Tani, Felipe Valencia Caicedo, and seminar participants at New York University and at IZA Institute for the Study of Labor. This paper represents the opinions of the authors alone and does not necessarily represent the views of Harvard University, the Center for Global Development, or their boards and funders. 


\section{Introduction}

Economics was born of studying the $18^{\text {th }}$-century efficiency losses from trade barriers. In the $21^{\text {st }}$ century, the efficiency losses from remaining restrictions on trade are relatively small. Much larger, but much less studied, the recent literature suggests, are the efficiency losses from restrictions on migration. Wage gaps on the order of $1,000 \%$ for similar workers between countries may imply large inefficiencies in the spatial allocation of labor, suggesting global costs of migration restrictions in the trillions of dollars per year (Clemens 2011). This is a new direction for migration economics, which has traditionally stressed wage effects in the host country and migrant selection.

In this paper, we review the literature on the global efficiency consequences of migration and assess a new strand of that literature. This is the new economic case for migration restrictions, which argues that migration barriers could in fact raise global economic efficiency, rather than reduce it. This new case articulates in economic terms what has long been a major political argument for migration restrictions. It argues that without restrictions, migration flows from poor to rich countries would be large and rapid, sufficient to transmit low productivity to rich countries via the cultures and institutions migrants could carry. This could offset and even negate the global efficiency gains from spatial reallocation of labor. This 'Epidemiological Case' is the argument that reducing migration restrictions could result in too much migration to raise global efficiency by reallocating labor for low to high productivity places, and could in fact reduce efficiency by lowering productivity in high productivity places.

We first consider, and reject, one possible existing counterargument to the new economic case for migration restrictions. This counterargument posits that, in the absence of migration restrictions, additional migration flows would be in fact be very low (or one author suggests, even zero). This, it is claimed, is because international wage gaps represent mostly or entirely the disutility of migrating rather than the disequilibrium produced by binding restrictions. This 'Contingent Valuation Case' is the argument that reducing migration restrictions could result in too little migration to decrease global efficiency (or increase it by much). 
We then present a new and different counterargument to the new economic case for migration restrictions. We propose a simple model of dynamically efficient migration to clarify what evidence could in principle support the Epidemiological Case for offsetting inefficiencies in migrant-destination countries. The Epidemiological Case requires evidence that migrants transmit large fractions of their home-countries' productivity, that this effect on productivity lasts long after immigration, and possibly that the marginal negative effect rises at high migrant stocks. The evidence in the literature, and new evidence presented here from global macroeconomic data and United States immigrant microdata, offer little empirical basis for the Epidemiological Case. In other words, the new efficiency case for migration restrictions has little basis, but not because few people wish to migrate. Rather, it has little basis because, while there is plausibly some volume and speed of migration that could offset the efficiency gains by eroding productivity in migrant-destination countries, that volume and speed would be far in excess of current rates. On current evidence, the efficiency case for migration restrictions in principle is in fact an efficiency case against most migration restrictions de facto.

We conclude by highlighting the infancy of this literature. While the efficiency effects of trade restrictions have inspired centuries of research and many thousands of studies, the efficiency effects of migration restrictions are just beginning to capture the attention of economists. A first step is to establish the global efficiency effects of migration restrictions. If these are large and negative, then reducing those restrictions is potential Pareto-improving (Kaldor-Hicks optimal), and an important area of research lies in designing mechanisms to reduce any gaps between potential and realized Pareto improvements. Such mechanisms, which have been critical to the broad global reduction of trade barriers, are a first-order determinant of the national-level efficiency effects of reducing migration restrictions. National and sub-national effects are certainly important, but not to the exclusion of global effects. 


\section{The efficiency cost of migration restrictions}

Economists studying international migration have traditionally focused on two areas. They have stressed income distribution effects in migrant-destination or "host" countries (Borjas 2003; Card 2005; Ottaviano and Peri 2012), and the 'quality' selection of migrants (Chiquiar and Hanson 2005). With a few exceptions, empirical researchers have mostly ignored the macroeconomic efficiency effects of international migration. "There seems to be an implicit premise in existing research," writes Hanson (2009) in a comprehensive review, "that knowing how immigration affects wages is sufficient to know how it affects national income."

But this literature is largely uninformative about the effects of migration on efficiency. This is for the same reason that measuring the partial-equilibrium effects of import tariffs on goods prices, or the relative quality of imported goods, would be largely uninformative about the overall effects of trade barriers on the wealth of nations (Bhagwati 2000).

\subsection{Macro evidence}

A recent literature signals an important shift in migration economics towards efficiency rather than distribution. This research estimates that international migration barriers create a very large global deadweight loss, amounting to substantial fractions of global production.

Remarkably, no one prior to Hamilton and Whalley (1984) attempted to explicitly characterize this deadweight loss. Their macro estimates suggested that something very important had been ignored: the gains to relaxing migration restrictions could rival or exceed world GDP. That is, a more efficient spatial allocation of labor could raise global output by 50-150\%. Decades passed before a series of follow-up studies confirmed the broad magnitude of the Hamilton and Whalley results with more refined macro models (Moses and Letnes 2004, 2005; Iregui 2005; Walmsley and Winters 2005; Klein and Ventura 2007, 2009; van der Mensbrugghe and Roland-Holst 2009; surveyed in Clemens 2011). The mag- 
nitude of these estimates has been corroborated in a series of recent studies (Benhabib and Jovanovic 2012; Kennan 2013; di Giovanni et al. 2015; Bradford 2015). Barriers to labor mobility, then, could cost the world on the order of half of potential production-leaving "trillion dollar bills on the sidewalk" (Clemens 2011).

These macro findings are congruent with sixty years of research on economic growth (Pritchett 2006). That literature has found that there are very large and persistent differences in Total Factor Productivity (TFP) between countries (Jones 2016). In cross-country growth accounting, the economic productivity of labor in rich countries exceeds that in poor countries by an order of magnitude. This difference persists even after accounting for differences in human capital stocks, and is not shrinking over time for most poor countries. In the early growth literature, total factor productivity was modeled as the common knowledge of "blueprints" or "technology", expected to diffuse somewhat quickly from leaders to followers. But this view has collapsed in the modern growth literature, with strong implications for migration. If TFP itself has limited mobility between countries, and given that full capital mobility will not produce income convergence Caselli and Feyrer (2007), the focus of inquiry into limits on the spread of global prosperity shifts to labor mobility. Barriers to labor mobility, in this sense, appear to constitute the most impoverishing categorical distortion to the global economy.

\subsection{Micro evidence}

On the micro side, there is now overwhelming evidence that the same worker's labor can be factor multiples more valuable in one country than in another. Workers from 42 developing countries in the United States earn PPP adjusted wages about PPP $\$ 15,000$ higher than observably identical workers in the origin countries earning about $\mathrm{PPP} \$ 5,000$ per year (Clemens et al. 2009). Workers from the lowest-productivity countries earn a "place premium" of around 1,000\% more simply by working in the United States rather than in their countries of origin. Location itself appears responsible for most of the productivity of any given worker on earth. Using globally-comparable microdata, Milanovic (2015) finds that country of residence is by far the most important determinant of global income inequality - dominating education, social class, and all other observable personal 
characteristics.

The magnitude of these estimates is robust to any plausible degree of migrant self-selection on the unobserved determinants of earnings. This is because the same finding obtains within narrowly-defined low-skill occupations with little scope for high returns to unobserved human capital. The real wage of McDonald's employees-people performing nearly identical low-skill tasks with little plausible return to unobserved talent-differs by an order of magnitude between rich and poor countries (Ashenfelter 2012, Table 3). The earnings of waiters between the top 10 and bottom 30 countries differ by roughly PPP $\$ 15,000$ per year (Pritchett and Smith 2016). Furthermore, the magnitude of these gains is similar in studies of naturally randomized visa lotteries with essentially no selfselection by migrants, both for workers with low skill McKenzie et al. (2010) and high skill (Clemens 2013). The microdata reveal such wage differentials both in the production of outputs that are strictly non-tradable (Ashenfelter 2012) and perfectly tradable (Clemens 2013).

These estimates suggest very large price wedges across space, pointing to very large efficiency losses. The size of the wedge, and the number of workers affected, imply Harberger triangles of macroeconomic importance.

This convergent evidence could be offset, in principle, by evidence that barriers to migration per se cause large gains for non-migrants. But the evidence on the effects of immigration on capital productivity is uniformly positive (Lewis and Peri 2015). This suggests that barriers to immigration produce important losses to capital in destination countries.

And for non-migrant labor, the consensus of the literature fails to detect large offsetting gains to average workers caused by restrictions on immigration. Existing estimates of the effect of immigration on average destination-country wages, cumulatively over decades, are uniformly close to zero (Borjas 2003; Ottaviano and Peri 2012). While there is meaningful debate about the distribution of effects across workers there is no quantitatively important debate about average effects. The published work suggesting even a small neg- 
ative impact on average wages is highly sensitive to functional form and discretionary parameter selection, as well as transitory pending capital adjustment (Borjas 2014; Card and Peri 2016). In the comprehensive survey of global evidence by Bodvarsson and van den Berg (2013, p. 157), "A comparison of the evidence from all the studies ... makes it clear that, with very few exceptions, there is no strong statistical support for the view held by many members of the public, namely that immigration has an adverse effect on native-born workers in the destination country." There is likewise no evidence of substantial, general labor market harms to non-migrants in the countries that migrants depart. Evidence from several developing countries, surveyed by Mishra (2014), indicates that emigration tends rather to improve wage and employment conditions for non-migrants.

\subsection{The policy importance of efficiency costs}

Distributional effects are important, of course. Card (2009) finds that inequality of U.S. residents has risen somewhat due to immigration (though inequality among native workers has not). But efficiency effects matter much more than the relative attention they have received in the literature would suggest. If a reduction in restrictions increases efficiency, this implies that policy can create Pareto-improvement by using aggregate gains to compensate losers. Economists use this standard of Kaldor-Hicks optimality in nearly all discussions in other policy areas - such as economic growth policies, competition market regulation/deregulation, international trade, monetary policy, and environmental regulation.

In those policy areas, economists' default policy response is instruments-to-targets - that is, each policy intervention (instrument) should address a specific market failure or redistributional goal (target) rather than having each policy consider all possible effects. For instance, in debates about trade policy import restrictions are often justified (usually by non-economists) as "saving jobs" but at such a large cost per job that import restrictions are generally a very inefficient instrument for job creation. Or often policies like "rent control" are politically advocated based on distributional impacts whereas economists point out that controlling rents is a very blunt and inefficient instrument to distribute income. Migration economics seems to have mostly missed this step. 
Often migration restrictions are espoused because, for instance, migrants could be a net fiscal cost as they would use more in social programs than they would pay in taxes. Empirically, migrants to OECD countries on average make a positive net fiscal contribution (OECD 2013). But even in theory, fiscal effects are a "second best" case for migration restrictions. The fiscal impact of migrants is the result of the design of tax/transfers and relaxation of migration restrictions, jointly. If migration is shown to have positive efficiency effects, then there exists some combination of relaxation of migration conditions and tax/transfer design that is Pareto-improving. Here again, inquiry into efficiency effects is the indispensable first step.

Permitting people to move from low-productivity places to high-productivity places appears to be by far the most efficient generalized policy tool, at the margin, for poverty reduction. Almost all policies intended to raise the incomes of people in poor places do so either modestly or not at all. A successful in situ anti-poverty program might raise the per-capita consumption of the world's poorest households by US\$54 per year (Banerjee et al. 2015). A two-year, six-component in situ intervention-guided by some of the top minds in development economics and backed by formidable financial and organizational resources - produced the equivalent annual consumption gain of the wage differentials of working in a rich versus poor country for one day. The harm to the poor from policies that produce such large losses for the poor cannot be systematically offset by the gains to any known in situ development intervention.

\section{The Epidemiological Case for efficient migration restrictions}

A new literature departs from the standard distributional case for migration restrictions. It responds to the efficiency literature on migration by offering a new economic case for migration restrictions. This posits that migrants from poor countries carry with them, and transmit to rich countries, that which makes poor countries poor. On this view, low productivity is something that spreads from poor countries to rich countries via cultures and institutions carried by migrants, like disease or pollution. This is known as the Epidemiological Model (Fernández 2011; Algan and Cahuc 2014, p. 85). 
If migrants sufficiently impoverished the countries they arrive in, this would offset the global gains to migration. In principle, if this effect had sufficient magnitude, migration barriers would raise global output relative to the counterfactual. The concern that migrants could spread harmful cultures and institutions is old, persistent, and politically important, expressed by analysts from Isaac (1947, p. 110-140) to Wolf (2015) and many in between. What is new is the articulation of this longstanding political concern in economic terms, important enough to impinge on the global efficiency effects of migration. Collier (2013, pp. 34, 68, 100) states it thus:

"Migrants are essentially escaping from countries with dysfunctional social models. It may be well to reread that last sentence and ponder its implications. ... The cultures - or norms and narratives - of poor societies, along with their institutions and organizations, stand suspected of being the primary cause of their poverty. ...So, uncomfortable as it may be, there are large cultural differences that map into important aspects of social behavior, and migrants bring their culture with them ... [with] the potential risk that the social model will become blended in such a way that damagingly dilutes its functionality: remember that in economic terms, not all cultures are equal."

Citing part of the above, Borjas (2015) models world GDP and parameterizes with $\lambda$ the fraction of poor countries' low Total Factor Productivity (TFP) that 'comes with' migrants, eliminating large fractions of productivity in now-rich countries. Simulating the global gain to eliminating migration restrictions, he writes,

"if $\lambda$ were equal to 0.5 , the net gain falls from $\$ 40$ trillion to $\$ 8.8$ trillion. In addition, if $\lambda$ were equal to 0.75 , the net gains become negative because now the entire world's workforce is largely operating under the inefficient organizations and institutions that were previously isolated in the South but have now spilled over to the North."

No theory or model is offered regarding how TFP is determined such that low income migrants reduce TFP. Moreover, no empirical evidence is offered to support the claim that transmission of this type exists. All that is demonstrated is that if migration reduces TFP then the gains are lower, but "if $A$ then $B$ " holds little interest unless $A$ is true.

One might suppose that any force eliminating a large share of global GDP could be detected. And if it could be detected, migration could be restricted at the point where 
marginal cost comes to exceed marginal benefit. But Collier (2013, pp. 41-50) sketches a model in which any effect of migration on institutions could be self-reinforcing and nonlinear. This is because, he argues, the arrival of some migrants today means even more tomorrow, and thus slower assimilation tomorrow. In this way, both the number of migrants and the impact-per-migrant rise over time, in an irreversible spiral. In this sense he compares relaxing migration restrictions to polluting the atmosphere with carbon: allowing migration flows in excess of an unknown "safe" threshold constitute "serious policy mistakes" that are later "difficult to correct". This danger would justify precautionary restrictions on migration even when its effects at the margin are positive: "Analogous to climate change, we do not know how large an unabsorbed diaspora would need to be before it significantly weakened the mutual regard on which the high-income societies depend" (Collier 2013, p. 257). Collier, too, offers no evidence regarding the point at which this irreversibility might occur, or what evidence could in principle contradict his claim.

Culture and norms have been shown to be transmissible by migrants (Fisman and Miguel 2007; Fernández 2011; Alesina et al. 2013b). What remains unknown is nearly everything about the magnitude of this transmission and its effects on the economy: 1) what fraction of origin-country TFP is determined by culture, 2) what fraction of any effect of culture on TFP arises from interactions between individuals of similar culture, and what fraction is transmitted with individuals to places where they interact with individuals of other cultures, and thus 3) what fraction of destination-country TFP is determined by transmitted culture. Beugelsdijk and Maseland (2011, pp. 213-225) review the many remaining problems with measuring 'culture'-including reducing of 'culture' to 'trust', and measuring the trust or trustworthiness of individuals with a simple survey question about whether other people can be trusted - as well as establishing a causal relationship between culture and economic performance. ${ }^{1}$

\footnotetext{
${ }^{1}$ Algan and Cahuc (2013) find that 'inherited trust' - the answer to a question about generalized trust of others in the descendants of 1930s migrants to the United States - correlates with contemporaneous economic outcomes in the countries of migrant origin. They interpret this as the effect of trust on growth, with a large magnitude. Fernández (2011, p. 505) observes that this correlation could arise from persistent traits of migrant-origin countries that 1) affected the trust of people in the 1930s and their descendants and 2) continue to affect economic performance in the home country today. Algan and Cahuc attempt to address this concern with long time lags-persistence of trust across four generations of U.S. immigrants. But Müller et al. (2012) show that this persistence is not robust to using different waves of the same trust survey, both before and after the wave used by Algan and Cahuc, raising questions about robustness of the result. Beyond this, any feature of a country that lastingly affects both trust and development for more
} 
There is observed persistence of incomes from migrant-origin countries to migrant-destination countries. People in rich countries whose ancestors came from poor countries tend to have lower incomes than other people in rich countries (Putterman and Weil 2010) - though this correlation is far from perfect as Indians have the highest household income of any ethnic group in America (Chakravorty et al. 2016). But this has no necessary implication regarding the quantitative contribution of portable 'culture' to this outcome. For example, the relatively low incomes of Americans of African and Native American descent could be mostly or even completely determined by destination-country institutions that massively expropriated human capital, land, and physical capital from many of the ancestors of people in those groups. The finding of persistence by itself is uninformative about the magnitude of a pure and transmissible effect of origin-country 'culture' on productivity, in either migrant-origin countries or migrant-destination countries.

Beyond this, there is a set of conjectures about the social/political conditions in which high productivity institutions/policies are created and maintained. For instance, one argument is that "homogeneity" leads to "trust" leads to "market supporting institutions" leads to high productivity. If such a causal chain exists, it is difficult to demonstrate. Countries whose residents exhibit a greater diversity of country-of-birth also exhibit better economic performance (Alesina et al. 2013a). Subnational regions that receive greater numbers of immigrants have experienced greater income growth (Lewis and Peri 2015). Countries that received more immigrants during 1990-2010 had more positive changes in indicators of economic governance (Clark et al. 2014).

This evidence certainly does not rule out the Epidemiological Case for efficient migration barriers at some level. Although the Epidemiological Case remains conjectural, it is sophisticated and sets out what must be established to build an efficiency case for migration restrictions of some degree. At low levels of migration, an additional migrant has no impact on Total Factor Productivity (or even might improve TFP). But it is possible that

than four generations could generate correlation in the absence of causation. For instance, the incidence of slavery going back several centuries affects levels of trust in Africa today (Nunn and Wantchekon 2011) as well as affecting economic outcomes in Africa today (Nunn 2008). And it is plausible that the experience of slavery affects levels of trust among Americans descended from African immigrants today. This would generate correlation between 'inherited trust' in the U.S. and contemporary economic outcomes in the countries of origin that does not arise from the causation of economic outcomes by trust. 
at some sufficiently high level of migration the underlying conditions that maintain high and rising TFP — whatever those are - might be nonlinearly undermined. In such a case, past some threshold, additional migration would begin to deteriorate host country TFP and hence might worsen economic well-being for the host country - or at the extreme, migration restrictions could be potential-Pareto-improving (Kaldor-Hicks optimal).

In other words, the Epidemiological Case could form a logically coherent basis for an efficiency case against open borders in general equilibrium. It cannot by itself provide an efficiency case for tightening or loosening migration restrictions from current levels, without empirical evidence on where the threshold stands. Similarly, believing that a firm's marginal costs can exceed the output price at some production level is not informative about whether current production is wastefully low, or how it could be known if it were too low. But it is of theoretical and empirical interest to explore further where the hypothesized migration threshold might stand, which is what we do in the second half of this paper.

\section{A faulty counterargument: Compensating Differentials}

The literature has raised one main objection to the new economic case for migration restrictions. It argues that migration restrictions do not greatly deter international migration, thus in the absence of migration restrictions there would be only limited additional migration. This idea rests on the Compensating Differential Case that migrants' disutility from migration is the principal constraint on international migration. This disutility is thus responsible for most of the large international wage gaps observed in the global labor market. On this view, migration restrictions do not raise global efficiency, but neither do they much reduce it.

In one of the two extant graduate-level textbooks on migration economics, Borjas (2014, p. 168) claims that the enormous wage differences between poor and rich countries may represent entirely a compensating differential for the psychic costs of migration. Borjas writes: 
"[L]arge wage differences across regions can persist for a very long time simply because many people choose not to move. In a world of income-maximizing agents, the stayers are signaling that there are substantial psychic costs to mobility, perhaps even on the order of hundreds of thousands of dollars per person, and that they are willing to leave substantial wage gains on the table. Kennan and Walker (2011, p. 232), for instance, estimate that it costs \$312,000 to move the average person from one state to another within the United States. ... If moving costs were indeed in that range, it is easy to show that the huge global gains from migration become substantially smaller and may even vanish after taking moving costs into account."

He then notes that if the psychic cost of migration from poor to rich countries is US $\$ 140,000$, "only half of what is typically reported in existing studies"-that is, in Kennan and Walker's study of U.S. interstate movement - then "the entire present value of the global gains from migration is wiped out" (Borjas 2014, p. 168). No other cost scenario is mentioned.

This quantitative claim is obviously erroneous. The absolute amount of willingness-topay depends on the absolute level of income. ${ }^{2}$ Consider identical logic applied to hospital births. The average cost of a hospital birth in the United States is near US\$20,000. If one inferred that the opportunity cost of a hospital birth in Malawi or Haiti is US\$10,000"only half of what is typically reported in existing studies [of the United States]" - one could conclude that the demand for hospital births in Malawi and Haiti must be essentially zero, because parent's "willingness to pay" cannot be multiples of their income. But in fact, $75 \%$ of Malawian women do demand birthing services in formal medical facilities (DHS 2011, p. 109). The willingness to pay for a hospital birth of rich people is obviously

\footnotetext{
${ }^{2} \mathrm{~A}$ correction this basic would not merit discussion if the error did not figure prominently in the field's leading graduate textbook. Caplan (2014) is the first to point out this error. He points out other errors, notably the fact that the relevant cost in this case is the marginal cost for potential migrants, while Kennan and Walker's figure reflects an average cost across individuals comprising migrants and non-migrants. For example, if one were interested in forecasting the demand for cars, one would be interested in the size of the group whose valuation of a car net of costs is positive at the margin, not the average valuation of a car across all individuals in the population. The average valuation net of costs could be zero, if some people are willing to pay less for a car than its price, even if it is positive in half or even most of the population. Using average valuations could result in a very large misestimate of automobile demand. Elsewhere, Borjas (2015) confuses the cost of policy barriers with non-policy migration costs. In a discussion of simulating the gains to migration without policy barriers, he describes the gains as "probably too optimistic because I have assumed that migration is costless". To illustrate the possibility of high migration costs, he writes, "Bertoli et al. (2013, p. 89) calculate that migration costs for the average low-educated Ecuadorian immigrant in the United States are almost 9 times the worker's salary." The source for the figure cited states that it includes the policy barriers faced by low-skill Ecuadorians to the U.S., and thus overstates the cost that would obtain without policy barriers.
} 
irrelevant to decisions made by people with a tenth of their income. Basic economics does not support the use of absolute willingness to pay valuations by United States consumers to characterize global preferences including for the very poorest.

More broadly, the claim that all global gains from migration can "vanish" due to offsetting disutility is identical to the claim that the global labor market is today at full spatial equilibrium. This claim implies that the existing global limits on international migration-passports, visa restrictions, limits on recognition of professional credentials, all deportations, all sea patrols, all fences - do not collectively have important effects on workers' decisions about where to locate. This would be the case if, as Borjas asserts is possible, migration itself generally conveys sufficient disutility that those policy barriers do not substantially alter workers' choice of location. This opinion is incompatible with existing evidence. Bertoli and Fernández-Huertas (2015) find that visa requirements cut bilateral migration flows by half, and additionally divert about $10 \%$ of potential flows to alternate destinations, while Bertoli and Fernández-Huertas (2013) find that visa requirements cut migrant flows to Spain by three quarters. Lawson and Roychoudhury (2016) find that visa requirements against a country reduce tourist travel from that country by $70 \%$. Mbaye (2014) finds that the median irregular migrant from Senegal to Europe accepts a $25 \%$ chance of dying en route, certainly incompatible with the notion that such migrants must be paid compensation in order to consider migration a worthwhile enterprise.

Other economists have likewise speculated that psychic costs to migrants could exceed even vast wage gains. Collier (2013, p. 176) posits that for poor-country emigrants in general, "continuing psychological costs would offset the gains for several generations: migration would not be an investment, it would be a mistake". No evidence is offered for the magnitude of such costs, nor for their persistence across "several generations". It is odd and implausible to imagine that the grandchildren of Haitian immigrants to the United States would in fact prefer to live in Haiti, despite their typical behavior of remaining in the United States, given that no barrier prevents their return to Haiti. While there are restrictions on moving to rich countries, there are typically not restrictions on moving back and when borders are open there are often substantial reverse and/or circular flows (Bandiera et al. 2013). 
The Compensating Differential Case encounters further difficulty in explaining why there is a $600-800 \%$ real wage gap between Haiti and the United States (which are separated by tight visa restrictions and naval interdictions), but historically similar Guadeloupe exhibits only a $60 \%$ difference in real wages with metropolitan France (to which Guadeloupian workers may move at will). Similarly there is a $300 \%$ real wage gap between observably identical Filipinos in the United States and the in the Philippines, but only a $50 \%$ wage gap between ethnic Guamanians in the mainland United States and in Guam (Clemens et al. 2009). Filipinos face tight policy restrictions on migrating to the United States, such that several categories of United States residency permits for Filipinos (F1, F3, F4) are so tightly rationed that the waiting list currently stretches $13-23$ years $^{3}$; Guamanians face no such restrictions. Only an exotic and conjectural model would posit that such large price wedges arise largely because Haitians happen to love their island home much more than Guadeloupians do, and Filipinos love the Philippines much more than ethnic Guamanians love Guam (Pritchett 2010).

To be sure, the literature finds that some disutility of migration exists and could explain some portion of international wage gaps (Clemens et al. 2009). Thus there remains uncertainty about the magnitude of additional migration that would occur in the absence of policy restrictions. Bertoli and Fernández-Huertas (2015) find that bilateral migration flows roughly double in the absence of visa requirements, in line with the many estimates of the global GDP gains from unrestricted migration on the order of $100 \%$. (Docquier et al. 2015), in contrast, estimate global GDP gains of $18 \%$ from unrestricted migrationprincipally due to assuming much lower unrestricted migration rates. ${ }^{4}$

These lower estimates arise from answers to a contingent valuation survey: a question about hypothetical desire to emigrate, "if you had the opportunity", asked in numerous

\footnotetext{
${ }^{3}$ Current wait-times for U.S. permanent residency permits are from: U.S. Department of State (2015), Visa Bulletin: Immigrant Numbers for November 2015, 86 (9): 1-9.

${ }^{4}$ For example, their baseline case assumes that in the absence of any migration barriers, just $1 \%$ of the population of India would find it worthwhile to migrate to any another country, at any point in the future, as well as just $8 \%$ of the population of Côte d'Ivoire (Docquier et al. 2015, p. 341). These predictions are strikingly low, given that income differentials are a powerful motive for movement (Kennan and Walker 2011; Grogger and Hanson 2011) — and essentially everyone in rich countries is at least one or two orders of magnitude richer than essentially everyone in India and Côte d'Ivoire. Even the very poorest people in Germany are richer than $97 \%$ of India (Milanovic 2015, p. 454) as well as $99 \%$ of Côte d'Ivoire (Milanovic 2013, p. 206).
} 
countries by the Gallup World Poll (Esipova et al. 2011). This survey shares the wellknown problems of most contingent valuation surveys on hypothetical preferences, whose results some leading economists have called "erratic and biased" (Arrow et al. 1993, p. 21) and "useless for serious analysis" (Hausman 2012). All such surveys suffer from the embedding problem, in which answers are highly sensitive to the context in which the question is placed (Kahneman and Knetsch 1992; Diamond and Hausman 1994). For example, a young Malian man responding to a simple poll question on migration desire might conceive of migration as an illegal and dangerous enterprise with the scant reward of degrading informal street-work. The response might differ if embedded in the relevant scenario: a world without policy barriers to migration, in which migration meant boarding a safe aircraft to take legal, formal-sector employment abroad and go back to visit home at will.

Moreover, survey respondents' preferences are known to depend on their reference frames for what constitutes a satisfactory outcome. Reference-dependent preferences can imply that willingness-to-pay for a good is positively related to expected probability of purchase (Bateman et al. 1997; Köszegi and Rabin 2006). That is, if the survey respondent does not expect to realistically migrate, his reference for aspirational income is the income of successful Malians in Mali, and he will place less stated value on the opportunity for higher earnings abroad. With low reference points, workers are known to forego earning opportunities (Camerer et al. 1997). But it is also known that direct exposure to other reference frames can change aspirational reference points, both in designed experiments (Jensen 2010; Wydick et al. 2013) and in a setting of naturally randomized migration (Stillman et al. 2015). In other words, in a counterfactual Mali where international migration was commonplace and successful, the young man's preferences could change - not only because migration would be a very different thing than it is now, but also because respondents' conception of satisfactory life outcomes would be different.

This suggests that the Compensating Differential Case remains unfounded. The arguments it comprises do not offer compelling evidence against the new economic case for migration restrictions. The theory and evidence we have suggests that policy barriers are major determinants of migration flows, and the migration flows would substantially rise 
in the absence of restrictions. This leaves intact the conclusions of the original efficiency literature on migration that there would be large first-order efficiency gains to reduced restrictions. But it also leaves intact the contention of the Epidemiological Case that such additional migration could in principle be large enough to produce offsetting inefficiencies in destination countries.

\section{Another approach: Estimating dynamically efficient migration}

The Epidemiological Case argues that without migration restrictions, there would be "too much' migration for those restrictions to be inefficient. We have considered and rejected an existing counterargument: the contention of the Compensating Variation Case that without restrictions there would be 'too little' migration to have large efficiency effects one way or the other. Here we propose an alternative and more rigorous way to evaluate the Epidemiological Case for globally efficient migration restrictions.

Before we proceed it is worth remembering why the current economic case for relaxed migration restrictions is so powerful. There are large persistent differences across places in the productivity of factors. This implies that movers from low productivity places to high productivity places have large gains in earnings. If these productivity gains are

"in the air" - that is have the nature of non-rival and non-excludable public goods - then allowing factors (including labor) to move to high productivity (when they want to) is potentially Pareto-improving. Movers gain, usually a lot, and no one else loses. If the productive efficiency gains to movers are large then all other objections are analytically "second-best" objections and "second-order" in empirical importance. Therefore to create a case for migration restrictions as a (potential) Pareto-improving action one has to undermine the notion of (relatively) exogenous, place-based, public-good-like factor productivity differences. This is what the Epidemiological Case endeavors to do.

The Epidemiological Case is logically possible, but its relevance to real-world migration restrictions depends on the magnitudes of the posited effects. This section explores what the key parameters might be in such a quantitative assessment. The sections thereafter 
will assess current evidence for the values of those key parameters. The key parameters are the rates of transmission, assimilation, and congestion, defined below in equations (1) $-(3)$.

We seek a dynamically optimal migration rate that maximizes world economic product during the process of globally equalizing the marginal product of labor. The optimal rate balances two effects. A higher rate of migration contributes to a greater buffer-stock of unassimilated migrants, assumed to strictly reduce TFP in the destination country by transferring in part the low TFP of poor origin-countries. This tends to reduce world GDP by making all workers in the rich destination country - migrants and non-migrants - less productive. The size of this effect grows over time as the labor supply of the destination grows. On the other hand, a higher rate of migration also reallocates labor from lowproductivity places to high-productivity places, tending to raise world GDP. If there is some point at which the marginal costs and marginal benefits of a higher migration rate are just equal, migration above or below that rate relatively impoverishes the world.

Formally, suppose there are two countries. Output in the rich home country is $Y=\bar{A} L^{\alpha}$, where $L$ is the labor stock, $\bar{A}$ is Total Factor Productivity, and $0<\alpha<1$. Output in the poor foreign country is $Y^{\prime}=\underline{A} L^{\prime \alpha}$, where $\underline{A} \ll \bar{A}$. A number of workers $M_{t}$ per year moves from foreign to home, contributing to a stock of unassimilated labor $\hat{L}$. Each year, a fraction $0<a<1$ of unassimilated labor assimilates (the "assimilation rate"), acquiring the same productivity of home natives.

\subsection{Defining the key parameters}

The stock of unassimilated labor in home is

$$
\hat{L}_{t}=M_{t}+(1-a) M_{t-1}+(1-a)^{2} M_{t-2}+\cdots
$$


Suppose the immigration rate to home, $m \equiv M_{t} / L_{t}$, is constant. The fraction of the home labor stock composed of unassimilated foreign workers $(0<\phi<1)$ is

$$
\phi \equiv \frac{\hat{L}_{t}}{L_{t}}=\int_{0}^{\infty} m(1-a)^{t} d t \approx \frac{m}{a}
$$

Migration from foreign to home changes total factor productivity in home to

$$
\widetilde{A} \equiv \bar{A}-(\bar{A}-\underline{A}) \frac{\tau \phi}{1-c \phi}
$$

where $0<\tau<1$ is the fraction of foreign total factor productivity that is transmitted to home embodied in each migrant (the "transmission rate"), and $c \lessgtr 0$ is the degree to which agglomeration of unassimilated foreigners nonlinearly reduces total factor productivity (the "congestion rate"). Note without congestion effects $(c=0)$, home total factor

productivity under migration, $\widetilde{A}$, reduces to a weighted average of pre-migration total factor productivity in home and foreign, with weight $0<\tau \phi<1$.

Figure 1 shows how home total factor productivity $\widetilde{A}$ is shaped by the stock of unassimilated foreigners $\phi$ in equation (3). There, $\gamma \equiv \bar{A}-\underline{A}$ denotes the gap in pre-migration productivity between home and foreign.

\subsection{The dynamically efficient transition}

We seek the migration rate $\mathrm{m}$ that maximizes global production. On one hand, migration into home raises global production by reallocating labor from low-to-high marginal product of labor. At time $t$ the population of home is $L_{t}=L_{0}(1+m)^{t}$, and the global gain-perperiod is

$$
\int_{L_{0}}^{L_{0}(1+m)^{t}} \bar{A} \alpha L_{t}^{\alpha-1} d L_{t}-\int_{\bar{L}-L_{0}(1+m)^{t}}^{\bar{L}-L_{0}} \underline{A} \alpha L_{t}^{\alpha-1} d L_{t}
$$

where $\bar{L}$ is the combined supply of labor in both countries. The first term of (4) is the gain to rich-country production from arriving labor, the second term is the loss to poor-country production from departing labor.

The per-period gain in (4) corresponds to the green area in Figure 2. In that figure, 
Figure 1: Home country total factor productivity as a function of the stock of unassimilated workers from foreign

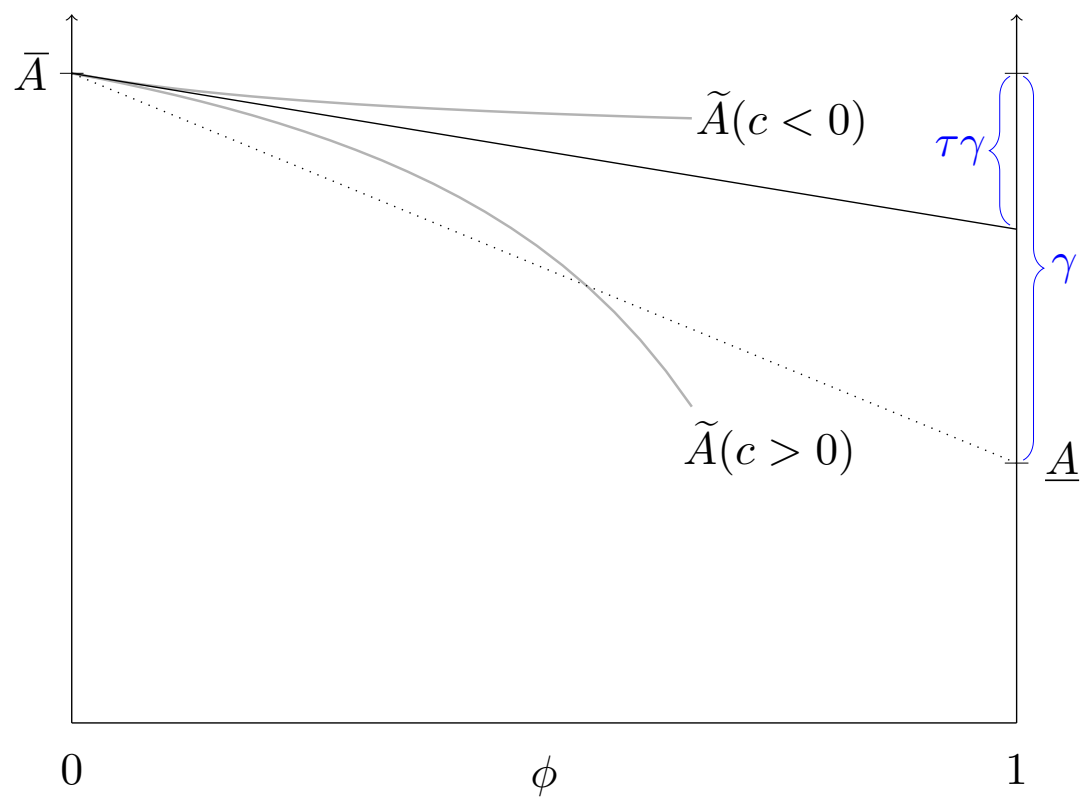

following Bhagwati (1984), the length of the horizontal axis is $\bar{L}$. The marginal product of labor is $Y_{L}$ in home, and labor supply in home is read right-to-left from origin $O$. The marginal product of labor is $Y^{\prime} L^{\prime}$ in foreign, and labor supply in foreign is read left-toright from origin $O^{\prime}$. As labor moves from foreign to home, the dotted vertical line shifts to the left.

Suppose that at time 0 , the initial population of foreign is a multiple $\beta$ times the initial population of home, thus $\beta \equiv\left(\bar{L} / L_{0}\right)-1>1$. The solution to (4) takes a tractable form using the first-order Taylor approximation that, for any $Z$ and small $x,\left(Z \pm(1+x)^{t}\right)^{\alpha} \approx$ $(Z-1)^{\alpha} \pm(Z-1)^{\alpha-1} \alpha x t$. Thus the gain-per-period (4) reduces to

$$
\alpha \operatorname{tm} L_{0}^{\alpha}\left(\bar{A}-\beta^{\alpha-1} \underline{A}\right)
$$

On the other hand, migration into home causes an offsetting decline in global production by reducing total factor productivity for all home residents, including past migrants. 
Figure 2: The global dynamic gains and losses from labor mobility

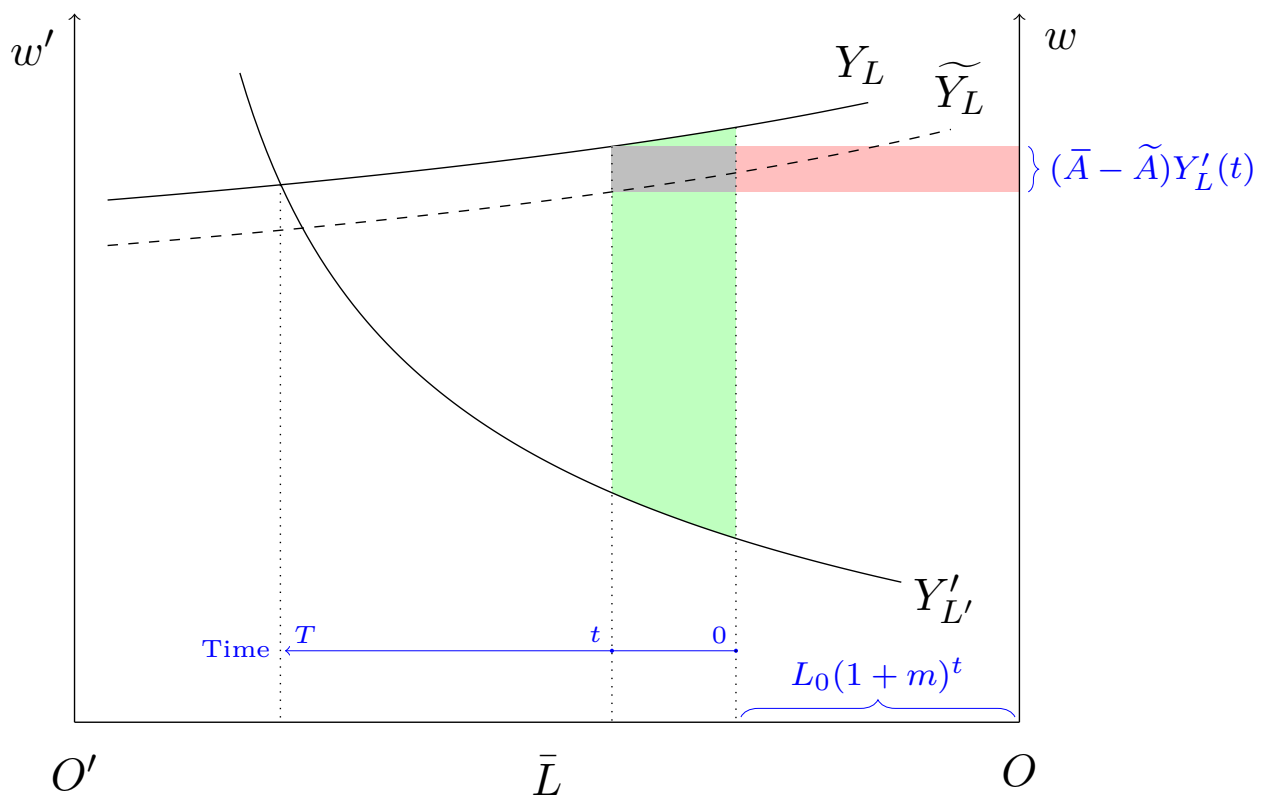

Normalizing $\bar{A} \equiv 1$ without loss of generality, the loss-per-period is

$$
(1-\widetilde{A}) \alpha L_{t}^{\alpha-1} \cdot L_{t}
$$

This is the red area in Figure 2. The time to complete the transition and equalize the marginal product of labor, as shown in the figure, is $T$.

The dynamically efficient migration rate $m$ sets the present value of benefits equal to the present value of costs. From (4) and (6),

$$
\int_{0}^{T} \int_{L_{0}}^{L_{0}(1+m)^{t}}\left(\alpha L_{t}^{\alpha-1}-\underline{A} \alpha\left(\bar{L}-L_{t}\right)^{\alpha-1}\right) d L_{t} e^{-\rho t} d t=\int_{0}^{T}(1-\widetilde{A}) \alpha L_{t}^{\alpha-1} \cdot L_{t} e^{-\rho t} d t .
$$

This reduces, utilizing the approximation (5) and for $T$ sufficiently large, to the condition $m \cdot\left(\alpha L_{0}^{\alpha} / \rho^{2}\right)\left(1-\beta^{\alpha-1} \underline{A}\right)=\left(\alpha L_{0}^{\alpha} / \rho\right)(1-\widetilde{A})(1+\alpha m / \rho)$. By $(2)$ and (3), the first-order approximation of dynamically efficient migration is

$$
m^{*}=\frac{a-\rho \tau \widetilde{\gamma}}{\alpha \tau \widetilde{\gamma}+c}
$$


where $\widetilde{\gamma} \equiv \frac{1-\underline{A}}{1-\underline{A} \beta^{\alpha-1}}$ is a modified measure of the initial gap in productivity $\left(\frac{d \widetilde{\gamma}}{d \gamma}>0\right)$.

The determinants of optimal migration in (8) are intuitive. The migration rate that maximizes world production during the transition is greater to the extent that the assimilation rate $a$ is higher. Optimal migration is lower to the extent that 1 ) the transmission rate $\tau$ is higher; 2) the initial productivity gap $\gamma$ is higher; 3) the discount rate $\rho$ is higher; and 4) congestion effects $c$ are smaller.

The corresponding optimal transition time $T$, inversely related to $m^{*}$, is

$$
T^{*}=\frac{\alpha \tau \widetilde{\gamma}+c}{a-\rho \tau \widetilde{\gamma}}\left(\beta-1-(1-\gamma)^{\frac{1}{1-\alpha}}\right)
$$

The determinants of $T^{*}$, too, are intuitive. Beyond those listed above for $m^{*}$ (in the inverse), the optimal transition time is longer to the extent that foreign starts out with a larger population than home (larger $\beta$ ) and with a lower total factor productivity than home (larger $\gamma){ }^{5}$

\subsection{A benchmark calibration}

Some of the parameters in the expression for optimal migration (8) are relatively well known; others are unknown. Here we fix the known parameters and ask what values of the unknown parameters would yield today's observed migration rates and other rates.

The known parameters are as follows. The gap between rich- and poor-country productivity, after accounting for differences in human capital, is roughly $\gamma=0.8$ (Hall and Jones 1999a, Table 1). Relative to the population of the high-income OECD countries, the rest of the world is about $\beta=6$ times larger. The labor share of income across the world lies close to $\alpha=0.6$ (Gollin 2002; Guerriero 2012). Finally, set the discount rate $\rho$ plausibly at 0.05 .

\footnotetext{
${ }^{5}$ At time $T$ the marginal product of labor in the two countries is equalized: $\bar{A} \alpha L_{T}^{\alpha-1}=\underline{A} \alpha L_{T}^{\prime \alpha-1}$. Substituting $L_{T}=L_{0}(1+m)^{T}$ yields $T=\left(\ln \left(\beta /\left(1+(\bar{A} / \underline{A})^{1 /(\alpha-1)}\right)\right)\right) / \ln (1+m)$. In first-order Taylor approximation $\ln (1+x) \approx x$ and $\ln (x) \approx x-1$ for $x$ small, thus $T \approx \frac{1}{m}\left(\beta-1-(\bar{A} / \underline{A})^{1 /(\alpha-1)}\right)$.
} 
The unknown parameters are the assimilation rate $(a)$, the transmission rate $(\tau)$, and the congestion rate $(c)$. While we will discuss plausible values for these parameters below, much less is known about them empirically.

Given the known parameters, what values of the unknown parameters would generate observed migration rates? The observed rate of migration from developing countries to principal migrant-destination countries is roughly $m_{0}=0.3 \%$ of the destination-county population per year. ${ }^{6}$ If this were the dynamically efficient migration rate, then equation (8) implies a relationship between the unknown parameters $(a, \tau, c)$ corresponding to a three-dimensional surface. This relationship can be visualized in Figure 3, which shows three different two-dimensional slices of the three-dimensional surface in equation (8). Each surface shown is defined by a different optimal migration rate. Holding $c=0.1$ in the top panel, the dotted line shows the pairs $(a, \tau)$ that yield an optimal migration rate of $0.3 \%$. The middle panel does the same holding $c=0.5$, and the bottom panel $c=0.9$. Intuitively, when congestion $c$ rises, either assimilation $a$ must rise or transmission $\tau$ must fall in order for the same migration rate to remain optimal.

Figure 3 also shows the $(a, \tau)$ pairs at each level of congestion that would yield optimal migration rates of $0,0.01,0.03$, and 0.05 . For example, the middle panel of the figure suggests that when the congestion rate $c=0.5$, if the transmission rate $\tau<0.5$ and assimilation rate $a>0.03$ then the optimal migration rate $m^{*}>0.01$.

\section{Parameters of the model: Concepts and literature}

We now briefly review the theory and existing evidence underlying transmission, assimilation, and congestion, before proceeding to new estimates of these relatively unknown parameters.

\footnotetext{
${ }^{6}$ In the United States over the last decade, an average of about 950,000 people per year have obtained permanent residence from countries other than Canada, European countries, and Japan (U.S. Dept. of Homeland Security Yearbook of Immigration Statistics 2013, Table 3), in a country of about 318mimplying $m=0.3 \%$. In the UK in the one-year period up to March, 2015, there were 183,000 net permanent arrivals of non-EU citizens (UK Office for National Statistics, Statistical bulletin: Migration Statistics Quarterly Report, August 2015), in a country of $65 \mathrm{~m}$-likewise implying $m=0.3 \%$.
} 
Figure 3: Benchmark calibration of the model

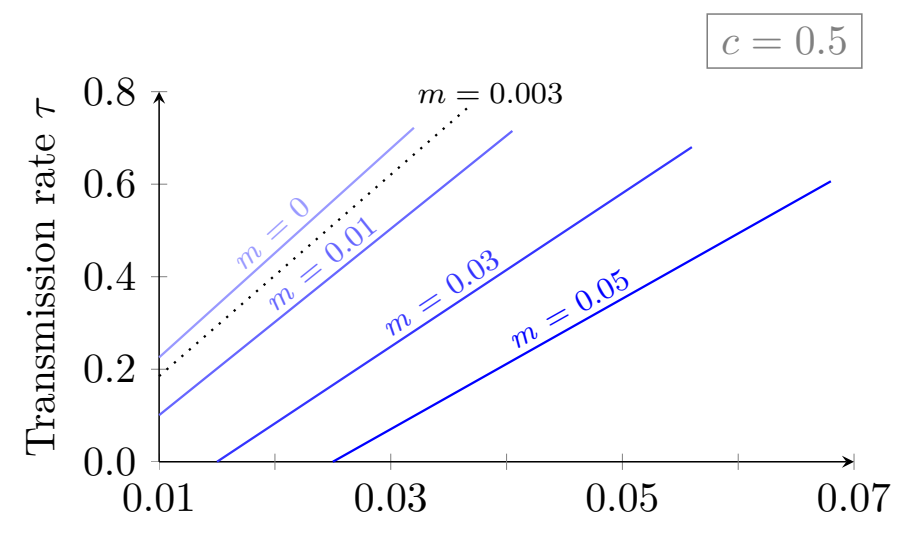

Assimilation rate $a$

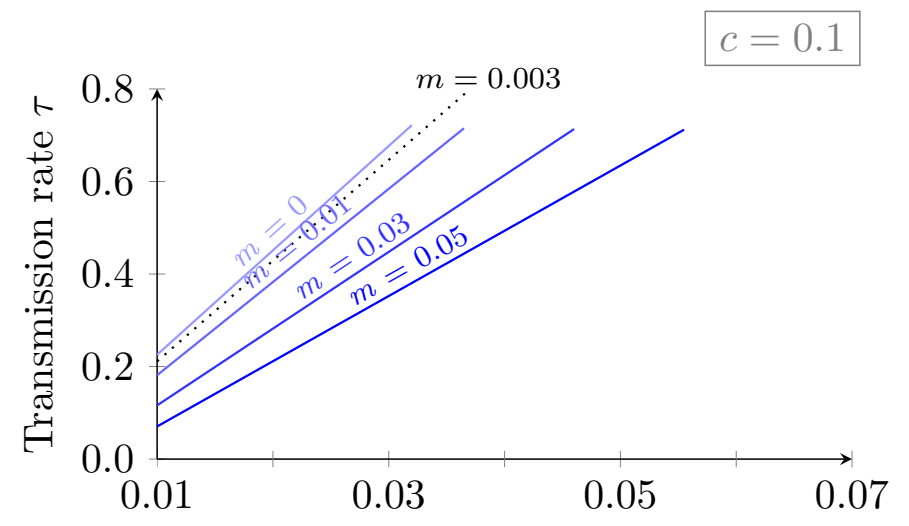

Assimilation rate $a$
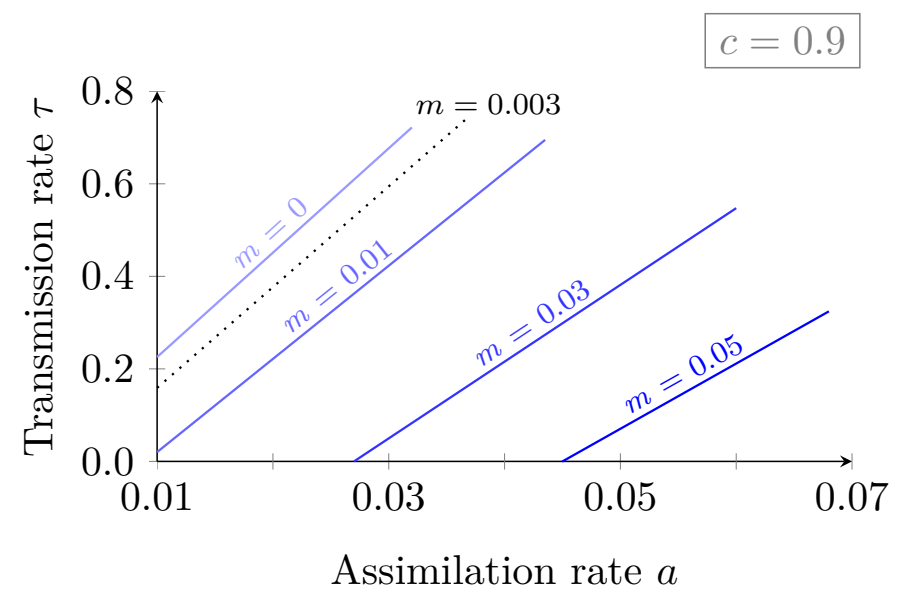


\subsection{Transmission}

The Epidemiological Case for efficient migration restrictions requires a model of development. That is, the idea that one country can transmit Total Factor Productivity to another via migrants requires a theory of what constitutes TFP. In the model above, we give the Epidemiological Case the benefit of the doubt, and simply assume that a large portion of poor-country TFP is transferred by individuals who move.

But this is unclear, and goes beyond what economists know about the nature of TFP. TFP tends to be measured as a residual: the unexplained part left over when the measurable causes of higher productivity are subtracted from production. This makes the components of TFP inherently difficult to characterize empirically. There are five main approaches to characterizing TFP in theory:

- TFP is "knowledge." The early approaches to TFP treated it as "blueprints" or more generally "codifiable knowledge" and the dynamics of TFP were "technical progress": the invention of, and improvement in the cost of production of, electricity, computers, solar power, etc. This is certainly some component of TFP, particularly for countries near or at the frontier of current productivity. But these models have difficulty explaining the persistence in differentials of TFP across countries (Jones 2016).

- TFP is "capability." Ricardo Hausmann, with various co-authors, has developed a theory that eschews entirely the aggregate production function approach (Hidalgo and Hausmann 2009). They argue that each product has its own recipe as a string of inputs and that more complex products have longer strings of needed "capabilities". Hence with non-tradable capabilities, places who possess more capabilities are capable of producing a larger array of products and hence more productive for each input.

- TFP is "mismanagement." Hsieh and Klenow (2010) find that an important determinant of TFP is the misallocation of inputs across firms and industries, while pointing out that economists' understanding of the causes of TFP differences remains limited. 
- TFP is "institutions." One model is that TFP is the result of "institutions" that are market-supporting like private property, the rule of law, and other policies and practices (and their associated embeddedness in organizations) that allow enable large scale investments, privately and socially productive organizations, and allow competition to facilitate innovation and weed out unproductive organizations (Jones 2016).

- TFP is "culture". A recent literature suggests that culture and norms affect TFP, and that culture and norms is transmissible to a nonzero degree through migrants (Algan and Cahuc 2013; Fernández 2011). No research has shown that migranttransmissible culture has affected TFP in migrant-destination countries.

It is immediately clear that some constituents of low TFP are not plausibly transmissible to rich countries. To the extent that TFP represents technology, it is not plausible that migrants from poor to rich countries cause rich countries to lose the knowledge ofsay-how to temper steel or produce electricity or grow wheat. To the extent that TFP represents the production capabilities it is likewise implausible that migrants could transmit low TFP. For example, if Peru cannot produce wide bodied aircraft because it lacks production capacity of certain necessary ancillary goods and services, nothing about this lack of capabilities would accompany migrants. Since economists know little about the relative importance of different types of TFP, it is difficult to quantify what fraction of TFP is transmissible even in theory.

In short, economists' current understanding of TFP does not offer compelling theoretical reasons to suppose that destination-country TFP can be substantially a function of migrant-transmitted portions of origin-country TFP. In theory, much of TFP can arise from goods that are nonrival and nonexcludable within countries, in which case standard factor-price equalization need not hold (Batina and Ihori 2005, pp. 233-250; Kremer 2006. Beyond this, historical episodes of mass migration do not reveal any such effects. Taylor and Williamson (1997) and Hatton and Williamson (1998) explore the economic impacts of the Age of Mass Migration. They find evidence of international wage convergence, but do not find evidence that this was caused by the migrant-mediated transmission of then-low TFP in Sweden and Hungary to the United States and Canada. 
To the contrary, there is a substantial literature suggesting that immigrants from lowTFP countries can raise TFP in the countries they move to. A recent literature finds that immigrants stimulate international trade, both in amount (Rauch 1999; Aleksynska and Peri 2014) and product scope (Bahar and Rapoport 2015); immigrant labor raises labor force participation by skilled female natives (Cortés and Tessada 2011); immigration can spur innovation (Kerr and Lincoln 2010); and immigration of low- and high-skill workers at observed levels typically raises total factor productivity (Peri 2012a; Lewis and Peri 2015).

It is simplistic to assume, as the literature often does, that the effects of migrants act through selection (Clemens 2014). Several studies investigate the effects of migration by the "best and brightest", as if migrants' effects at the destination were embodied within them and would occur wherever they were. It is outlandish to suppose that Sudanese telecom entrepreneur Mohamed Ibrahim could have made the same contribution if he had not left Sudan for the United Kingdom, or that Saint Lucian Nobel laureate Arthur Lewis could have made the same contribution had he not left Saint Lucia. They did not raise productivity in their destination countries because they had it within them and transferred it there. If this were the case they would have been equally productive at home. Their effects on productivity at the destination do not reveal some transmissible portion of productivity; quite the opposite, they illustrate how important components of productivity are not transmissible.

\subsection{Assimilation}

If low TFP is in fact transmitted to migrant-destination countries, what portion of it is absorbed there? Even if a component of TFP is transmissible in principle, it might not be transmitted in practice because destination-country TFP is resilient to change. Migrants can adjust to rich-country productivity - in some ways immediately, in other ways over time.

Take institutions. What the organizations, laws, policies and practices of advanced economies and polities and administration do is make it possible for people to carry on 
long-term and complex economic transactions without any face to face contact or interpersonal relationship at all. Seabright (2004) points out that human evolution occurred in a period in which people interacted with at most a few hundred people. Without the intermediation of "institutions" complex societies of any scale are impossible. While there is no doubt the social and personal and associative life is important to human well-being, this "affective" component of human experience is generally at a scale far smaller than the typical nation-state. It is precisely the objective of a modern bank to eliminate personal trust from financial transactions, precisely the objective of a modern post office to eliminate personal trust from delivery of personal messages.

Moreover, most models of "institutions" or "norms" exhibit multiple equilibria with high transition barriers between equilibria. Once established, norms persist even if the underlying conditions for their creation are no longer present. For instance, which side of the road to drive on is a norm or convention and some countries have adopted "right side" and others "left side." Every migrant from a left-side to right-side country quickly adopts to driving on the right side. One can easily imagine two countries: A is a right-side country with 100 people and B a left-side country with 100 people. Every year 5 people move from $\mathrm{A}$ to $\mathrm{B}$ and 5 from $\mathrm{B}$ to $\mathrm{A}$. At the end of 20 years every person in A is from B and vice versa. But it is likely that in A people still drive on the right side even though every single person in A was a "native" left hand side driver. For each set of migrants, it is immediately and permanently suboptimal to play by origin-country rules. Assimilation is instantaneous because any other strategy is a losing one.

In other words, "institutions" are ontologically social. Individual people do not and cannot "have" institutions in the way that an individual can have blond hair or the flu or a university degree, nor even in the way they can own a house or a share of a firm. Institutions are patterns of behavior across individuals and individuals either "participate in" or "conform to" institutions. To some extent the evidence of the very long-term persistence of the impacts of "institutions" suggest that "institutions" once adopted are very robust (Helliwell and Putnam 1995; Dell 2010). Part of this robustness must be the willing (conscious or not) adoption of the norms by many different people over many different years, including many people not born and raised with those norms. 
As we consider empirical evidence on assimilation in the model, we note three key features of this parameter. First, the meaning of 'assimilation' in this setting is precisely defined by equations (1)-(3). It is the rate at which the stock of migrants from foreign come to resemble home natives in economic productivity only. That is, it does not require assimilation in every sense, but only those senses that determine labor productivity. Second, more specifically, assimilation here covers determinants of economic productivity apart from observed levels of education. The productivity gap parameter İs is what remains after differences in observed human capital are accounted for. Third, the simple model above has assumed infinitely-lived migrants. In reality, assimilation of people whose presence in the destination country is caused by migration will be a composition of both the rate of individual-level assimilation and the rate at which each generation of migrants is replaced by an assimilated next generation.

Thus the assimilation of interest is precisely cross-sectional assimilation of the overall stock of migrants, not longitudinal assimilation of individual migrants. Individual-level assimilation has been a focus of the literature due in part to policy interest in assisting individuals to assimilate. Cross-sectional assimilation overstates individual-level assimilation to the extent that unassimilated individuals emigrate (Lubotsky 2007). But if individuals who embody low TFP re-emigrate, they no longer affect destination-country TFP. It would therefore be incorrect to use longitudinal, individual-level assimilation rates to parameterize the model in the preceding section.

It is well known that some of migrants' cultural attitudes, such as factors that affect answers to survey questions about their generalized trust in others, resists full assimilation in destination countries for multiple generations (Guiso et al. 2006; Fernández 2011; Dohmen et al. 2012). On the other hand, the literature finds high rates of crosssectional earnings assimilation among immigrant workers. LaLonde et al. (1991) find that most of the immigrant-native earnings gap is gone within 10 years of arrival, for all five ethnic groups they study (European, Asian, Middle Eastern, Mexican, and Latin American/Other Caribbean).

The slow assimilation of cross-sectional culture and 'trust' but rapid assimilation of cross- 
sectional earnings imply one of three things. First, perhaps individual-level trust is not a simple or quantitatively important determinant of migrants' productivity. Beugelsdijk and Maseland (2011, pp. 213-219) review several problems with interpreting answers to survey questions about trust. Whether or not an individual trusts others is not the same as whether that individual is trustworthy, and perhaps trustworthy people can be productive even when their ideas about who deserves their own trust are slow to change. Furthermore, Butler et al. (2016) find that the relationship between trust and individual income is nonlinear, suggesting that both low and high levels of individual trust can harm those individuals.

Second, it is hypothetically possible that any negative effects of culture and 'trust' on productivity are entirely external to individual earnings; that is, people who are untrusting harm others' productivity without harming their own productivity. Then migrants' unassimilated culture could continue to reduce others' incomes even after their own incomes had assimilated. This would not sit easily with existing theories of how trust affects growth, many of which require systematic defection from trust games in which the defector internalizes costs (e.g. Algan and Cahuc 2013, p. 533).

Third, perhaps there are nonlinear effects of unassimilated migrant stock on earnings. That is, when the stock of unassimilated migrants is low, perhaps full cultural assimilation is unnecessary in order for migrants to remain productive, but this changes at higher migrant stocks. We explore that possibility below.

\subsection{Congestion}

Intuitively, nonlinearities could arise in either transmission or assimilation. When migration reaches a certain scale, norms could be transmitted that otherwise would not be, and assimilation could slow as migrant-native contact changes in extent or nature.

Borjas (2015) asserts that no evidence exists that could inform research on where such saturation points might lie. He writes, "we know little (read: nothing) about how host societies would adapt to the entry of perhaps billions of new persons." It is certainly 
untrue that economists know "nothing" about the effects of large-scale migration; much larger relative migrations have occurred. From 1820 to 2015 the population of Australia grew, mostly due to immigration, by 7,200\% - from 334,000 to 24 million. Many of Australia's early migrants were criminal outcasts; many recent migrants come from very poor countries. But Australian productivity stands today near the global frontier.

That scale of migration is much larger than anything possible today at the global level. The movement of "billions of new persons" to today's rich countries, as defined by the World Bank, might involve a migration-induced population change of just 100 or 200\% over generations. Historical episodes of migration on this order of magnitude, from lowTFP countries to high-TFP countries, have revealed no sign of TFP collapse even in the destination countries most intensively receiving migrants (Taylor and Williamson 1997; Hatton and Williamson 1998).

Indeed it is unclear how one could demonstrate empirically that congestion externalities are large. First, there is large variation in the percent foreign born across OECD countries already. Canada is over 19 percent, Switzerland and Australia are over 26 percent. At these observed levels, there is no clear evidence of lower productivity in higher-immigration countries; if anything, the opposite is true. This implies that if a congestion threshold of some kind exists, most or all countries are far from it.

Second, the percent foreign born in many cities in the United States is already well over a quarter, including for New York, Los Angeles, Boston. In Canada, Toronto is near 50 percent foreign born; Vancouver is over 40 percent. It is not clear exactly how the causal mechanisms whereby the stock of foreign born is supposed undermine TFP are supposed to work, but there is little evidence these cities have deteriorating TFP relative to other cities.

Third, there are entrepôt city-states such as Singapore and the Dubai Emirate that have a very high percentage of the foreign born (Singapore is over 40 percent, Dubai over 80 percent) and are extremely productive. Dubai suggests it is possible to create very high TFP without essentially any underlying common social culture at all. These examples do 
not by any means rule out nonlinear congestion effects. But they do suggest that such effects do not set in automatically even at high migrant stocks. If saturation points exist and have substantial TFP effects, this remains to be shown.

\subsection{Stylized facts on poor-country migrant stocks and TFP}

The model in Section 5 implies that migration barriers could be efficiency-enhancing given high transmission, low assimilation, and/or high congestion. The literature reviewed above offers little compelling theory or evidence of such values for these parameters.

It is unclear what would constitute evidence that people moving from poor countries to rich countries can greatly alter rich countries' TFP. The channels and mechanisms of action have not been well specified. Moreover, the claim of the Epidemiological Case is explicitly non-linear. It does not argue that the marginal migrant would undermine the economic, political, or social institutions that support high productivity, but rather that past some threshold migrants would begin to undermine productivity.

Countries in the world already differ by an order of magnitude in the proportion of the foreign born in their population. As yet there is no evidence this higher penetration of foreign born from low productivity countries is associated with lower TFP growth in the host countries. This of course does not rule out that there is some threshold.

But it does rule out that most OECD countries are near any such threshold. Figures 4 and 5 show the bivariate scatter plot and the predicted quartic regression line of the growth of TFP 1990 to $2011^{7}$ in the twenty one (old) OECD countries ${ }^{8}$ and the ratio of foreign born from low TFP (Figure 4) or low GDP per capita (Figure 5) countries $^{9}$ in $2000^{10}$.

\footnotetext{
${ }^{7}$ We use the variable RTFPNA from the Penn World Table 8.0 data for each country and calculate the least squares growth rate over the entire period.

${ }^{8}$ These are the countries who were members of the OECD before 1990 .

${ }^{9}$ In these graphs we used the threshold of the 1980-2000 average being less than 0.75 of the USA level of TFP (year by year) or 2000 USA GDPPC.

${ }^{10}$ We use the estimated bilateral migrant stocks estimated by the UN Population division for 2000 (http: //www.un.org/en/development/desa/population/migration/data/estimates2/estimatesorigin.shtml). For TFP we use either the average of the variable CTFP or the predicted TFP based on GDP per capita (as many countries are missing TFP estimates) or GDP per capita (using RGDPE) from 1980 to 2000 to represent the TFP or output in the sending countries during the period in which those who were migrants
} 
Figure 4: TFP growth in rich countries versus migrant stock from low-TFP countries

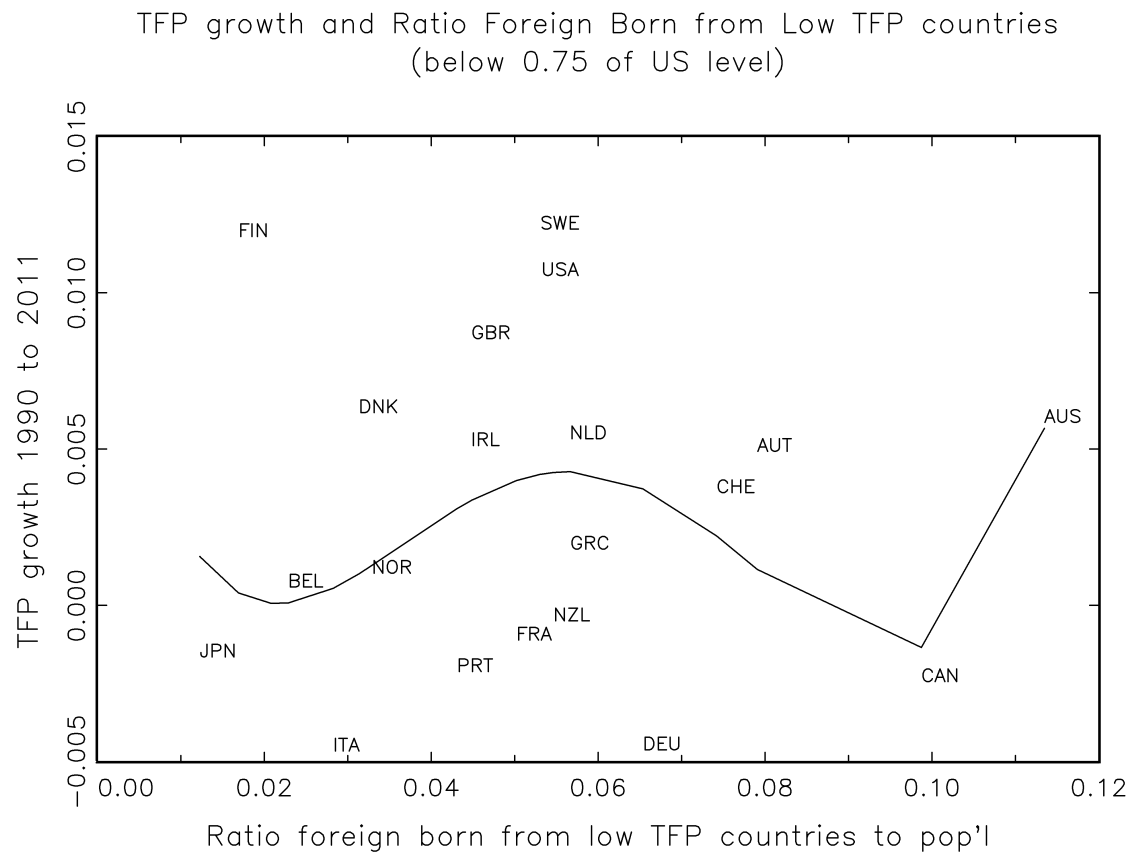

In Figure 4 one can see that Australia (AUS) has over 11 percent of its 2000 population from low TFP countries whereas Japan has 1.2 percent of its 2000 population from low TFP countries. In Figure 5 one can see Australia, Canada, the USA and Austria have more than 8 percent of the population from countries below the GDP per capita threshold while Finland and Japan have just above 1 percent.

A stylized fact emerges from these figures. There is no relationship between poor-country migrant stock and TFP growth in migrant-destination countries, across a wide range of observed stocks. If the host countries with larger populations were experiencing a deterioration in TFP due to the effect of migrants then one would expect that, past some threshold, there would be a negative slope. Since the effect, were it to exist at all, is postulated to be non-linear we fit a quartic through the data (obviously with few data points this leaves few degrees of freedom). The data really say there is no discernible relationship at all as the F-tests fail to reject the null of no relationship for any specification from linear to quartic for either definition of the "low income" foreign born. The graphs in 2000 likely moved. 
Figure 5: TFP growth in rich countries versus migrant stock from low-income countries

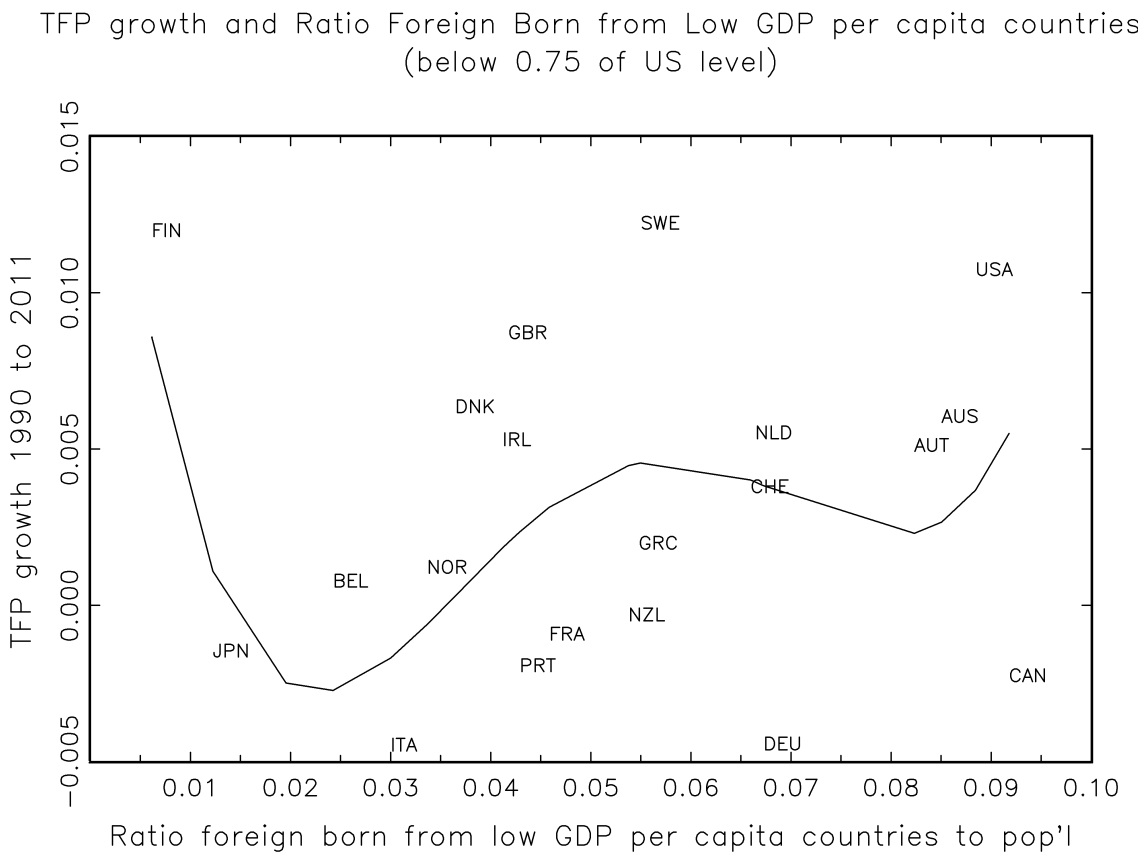

suggest that, if anything, TFP growth has been higher in countries with medium to high stocks of the low income country foreign born (e.g. Sweden, Great Britain, USA higher than Japan, Italy, Norway) and that the slope is still upward at the highest levels observed in the data.

These simple relationships reveal no traces of the large effects of poor-country migrants that should be expected if transmission is high and/or assimilation is low. They also reveal no sign of congestion affects across an order of magnitude in migrant stock sizes.

We present these data not as powerful evidence against any effects of immigration on TFP, but rather to make three simple points. First, so far the new case for migration restrictions is based on no evidence at all. It is a conjecture, and not one for which even stylized facts have been presented in support. Second, calibrating such a model (as we attempt to do below) will be difficult. If no country or region is past the threshold after which the "congestion" effects are present, this will be all that can be said, and this cannot be evidence there is no such threshold beyond the sample. Third, and more positively, 
if no countries are yet demonstrably above any threshold, then because there is massive variation across countries then most countries are far from any such threshold - if it exists.

\section{Parameters of the model: New evidence}

Here we present new evidence on broadly plausible values of the transmission, assimilation, and congestion parameters in the model. We use United States census data on immigrants from most of the poorest countries from which there are large immigrant stocks in the United States. We also include Mexico, though it is substantially more developed than the others, as a useful point of comparison.

\subsection{Transmission}

Here we use U.S. census data to make approximate measurements of the productivity transmission and assimilation rates. Table 1 uses the standard assimilation specification of Borjas et al. (1992), running the regression

$$
\ln w=\omega+\zeta I_{\text {for }}+\lambda y+\mu y^{2}+\boldsymbol{\iota}_{\text {age }}^{\prime} \boldsymbol{I}_{\text {age }}+\boldsymbol{\iota}^{\prime}{ }_{\mathbf{e d u}} \boldsymbol{I}_{\mathbf{e d u}}+\iota_{\mathrm{fem}} I_{\mathrm{fem}}+\varepsilon
$$

where $w$ is earned income per year (US\$); $I_{\text {for }}$ is an indicator variable for foreign-born; $y$ is years since immigration (zero for U.S. born); $\boldsymbol{I}_{\text {age }}$ and $\boldsymbol{I}_{\mathbf{e d u}}$ are vectors of indicator variables for age groups and for the highest level of education completed; $I_{\mathrm{fem}}$ is an indicator variable for female, and $\varepsilon$ is an error term. Each column of Table 1 restricts the sample to individuals born in the U.S. and in one other country, with the other country identified at the top of the column. We can then use the estimates in Table 1 to approximate the transmission rate $\tau$ for each country. We measure productivity with earnings five years after arrival. Migrants might experience an immaterial wage penalty immediately upon arrival as they learn the basics of U.S. job search, finish their education, etc.; we assume this penalty has ended after five years. We thus estimate the initial

earnings gap for a new immigrant as $\delta \equiv 1-e^{\hat{\zeta}+5 \hat{\lambda}+5^{2} \hat{\mu}}$. For example, a recent immigrant from Bangladesh - a 30 year-old male with a high-school education-earns $45.6 \%$ less than a U.S. native of the same description. 


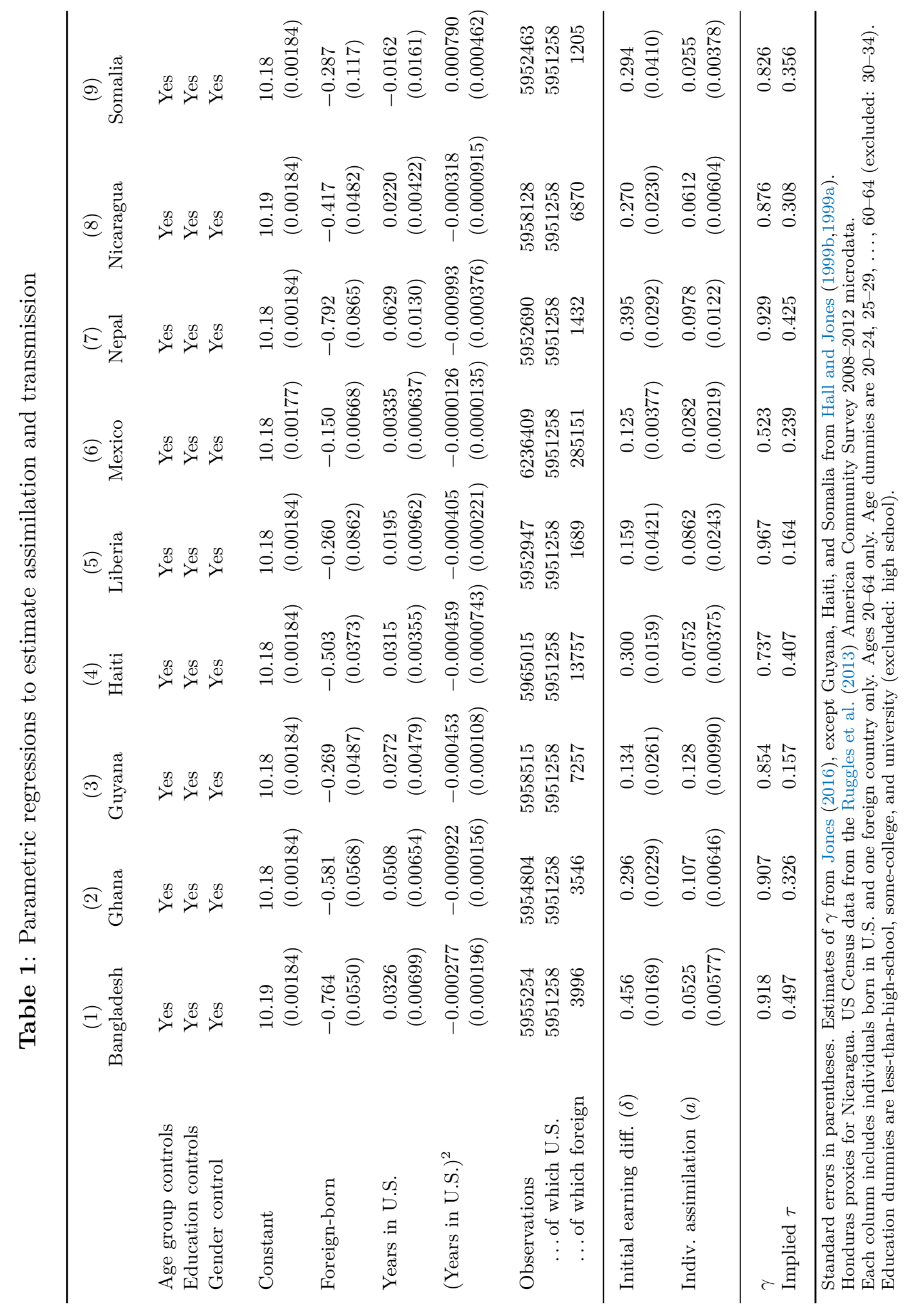


We then relate this new-immigrant earnings gap to productivity in the country of origin. To do this, we require estimates of the gap between total factor productivity in the U.S. and migrants' country of origin. Hall and Jones (1999b,1999a) and Jones (2016) measure the ratio of total factor productivity in each country to the value in the U.S., after accounting for differences in human capital. For example, Jones (2016) estimates that total factor productivity in Bangladesh is 0.082 of its value in the U.S., thus $\gamma=0.918$.

The fraction of this gap that 'comes with' the migrant is $\tau=\frac{\delta}{\gamma}=\frac{0.456}{0.918}=0.497$. The final rows of Table 1 carry out this calculation.

\subsection{Assimilation}

First we check that Table 1's parabolic specification of assimilation time is suitable. Figure 6 shows semiparametric regressions without the assumption of parabolic assimilation, corresponding to columns 2 and 8 of Table 1 . Figure 6 is made by running

$$
\ln w=\omega+\zeta I_{\text {for }}+\iota_{\mathbf{y}}^{\prime}\left(I_{\text {for }} \cdot I_{\mathbf{y}}\right)+\iota^{\prime}{ }_{\text {age }} \boldsymbol{I}_{\text {age }}+\boldsymbol{\iota}^{\prime}{ }_{\text {edu }} \boldsymbol{I}_{\mathbf{e d u}}+\iota_{\mathrm{fem}} I_{\mathrm{fem}}+\varepsilon
$$

where $\iota_{\mathbf{y}}^{\prime}$ is a vector of indicator variables for years since immigration (in five-year categories). The nonparametric regression line in the figure is made by exponentiating the elements of the estimated coefficient vector $\hat{\boldsymbol{\iota}}_{\mathbf{y}}$. The horizontal line in the figure is the corresponding predicted wage of an otherwise observably identical U.S. worker $\left(e^{\hat{\omega}}\right)$. Immigrants from these countries earn less than otherwise similar U.S. workers shortly after arrival, but their wages rise asymptotically toward those of their U.S. counterparts. This suggests that the parabolic specification in Table 1 is useful.

We can then use the coefficient estimates in Table 1 to approximate individual-level earnings assimilation for immigrants from each country. The gap between immigrant and native earnings shrinks over time according to the parabola defined by $\hat{\lambda}$ and $\hat{\mu}$, which yields a half-life for the earnings gap, and that half-life yields the corresponding annual assimilation rate. The half-life of the immigrant-native earning gap is the duration over 
Figure 6: Semiparametric regressions of conditional earned income on years since immigration

(a) Ghana

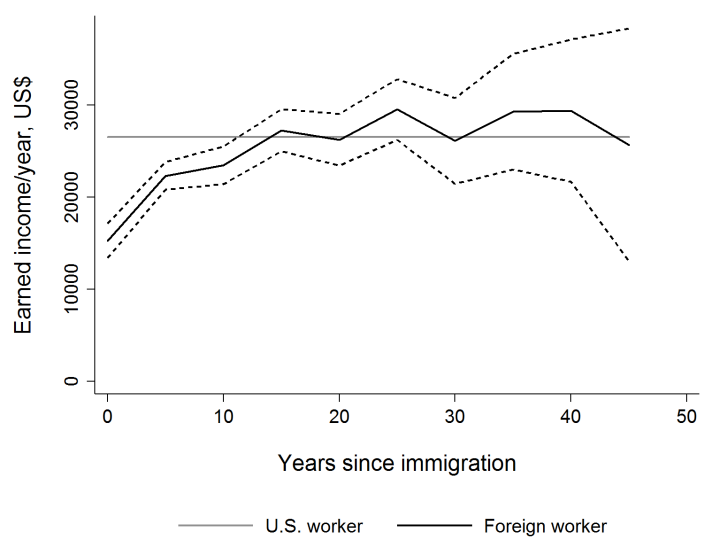

(b) Nicaragua

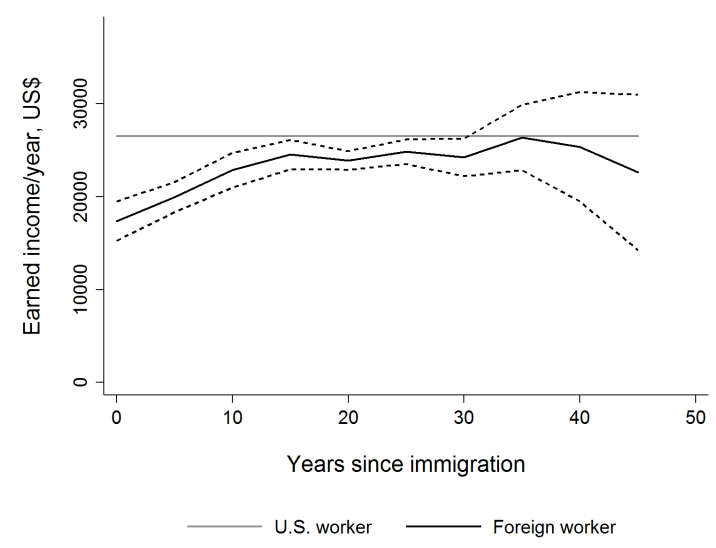

which the assimilation parabola rises to close half of the initial gap, thus

$$
\hat{\mu} t_{1 / 2}^{2}+\hat{\lambda} t_{1 / 2}=\frac{|\hat{\zeta}|}{2}
$$

and the solution $t_{1 / 2}$ yields the estimated annual, individual-level assimilation rate by $a=-(\ln 2) / t_{1 / 2}$. These results are shown in the Individual Assimilation row of the table.

\subsection{Congestion}

What is a reasonable magnitude for the congestion effect? Figure 7 shows $\widetilde{A}$ from equation (3), for different values of the congestion rate $c$. The figure assumes productivity gap $\gamma=$ 0.8 and transmission rate $\tau=0.4$. Inspection of the figure suggests that a congestion value of $c=0.9$ would be quite large: At such a value, as the immigrant fraction approaches $50 \%$, half of GDP is wiped out. Roughly half the population of Toronto, Canada is foreignborn, mostly from developing countries, and factors in Toronto are certainly not half as productive as factors in otherwise similar cities with fewer migrants. This suggests, prima facie, that reasonable values for $c$ lie somewhere well under 0.9. 
Figure 7: Implications of different assumptions about congestion

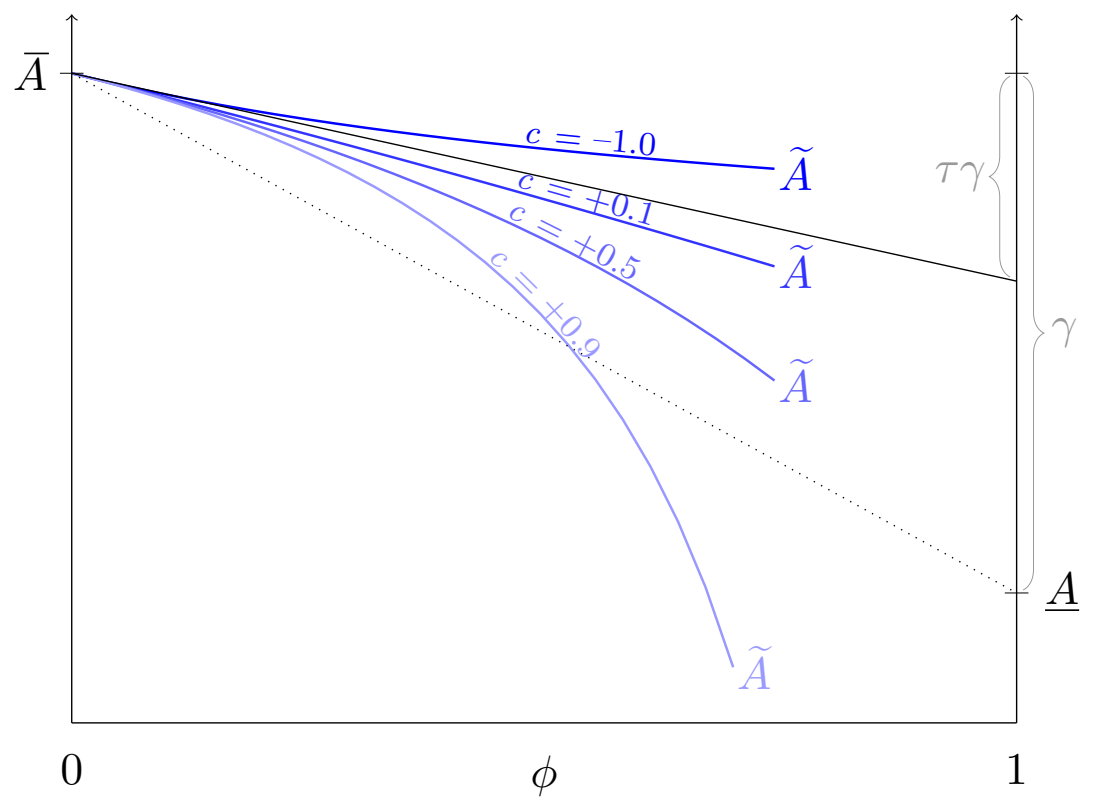

We can go beyond this rough bound with two assumptions, under which one could explore the congestion effect by comparing high-immigration areas like Toronto to lowimmigration areas of the same country. The first assumption, 'locality', is that a large part of Toronto immigrants' effect on Canada's TFP arises by affecting the productivity of factors located in Toronto, not somewhere else in Canada. The second assumption, 'exogeneity', is that conditional on having moved to Canada, immigrants do not choose where to locate based on how their decision would affect natives' productivity.

The locality assumption is reasonable to first order. It would not fit with the literature to suppose that the productivity effects of immigrants in Toronto act primarily through externalities that are incident upon people who do not live in Toronto. The potential mechanisms for congestion important in the literature - such as nonlinear 'critical mass' effects of trust, gender norms, entrepreneurship, or reduced assimilation - would all affect economic activity at the level of the locality where migrants live and interact with nonmigrants. Other channels could exist that would not be detected in local-area data, such as if a critical mass of immigrants elects incompetent national-level politicians, or if a critical mass of migrants spurs innovation that shifts national TFP. But such indirect and 
Figure 8: Incomes in different areas of the U.S. by immigrant concentration, 2008-2012

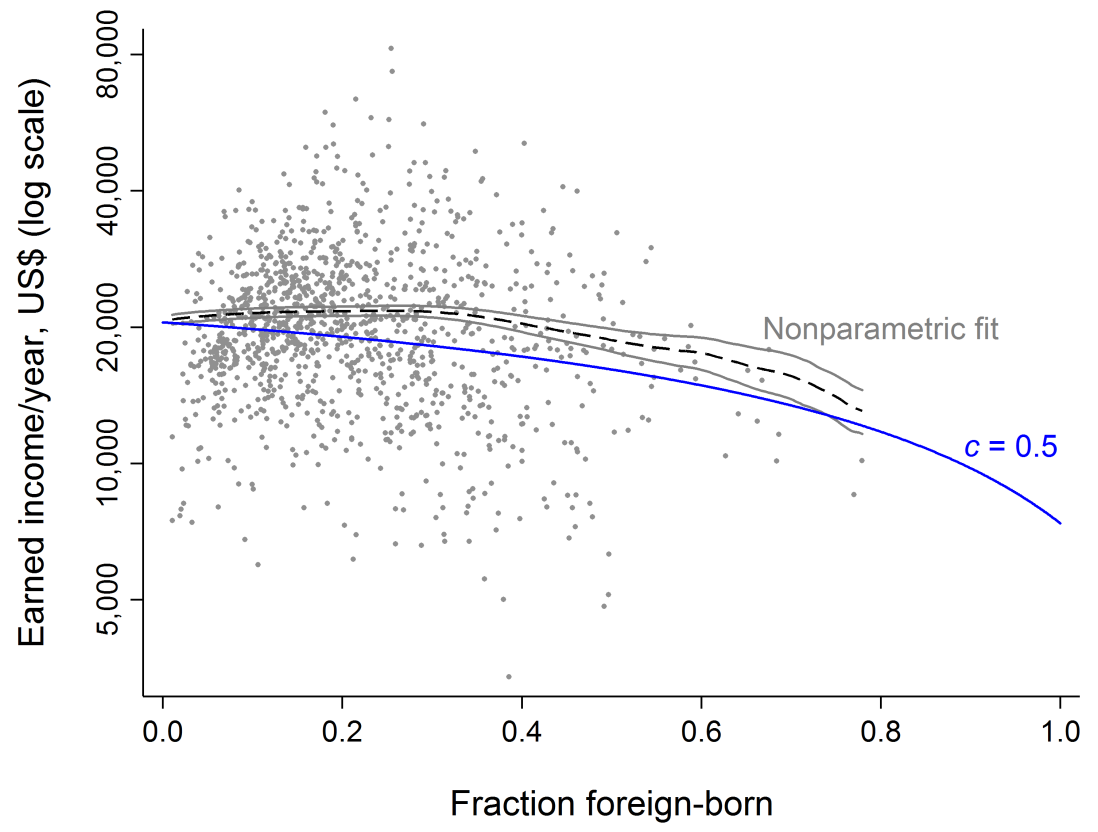

Observations by US Census 'Public Use Microdata Areas' (PUMAs), which are 1,185 geographic subsets of the country defined such that each contains more than 20,000 residents (for five-year pooled data). Data from US Census American Community Survey pooled 2008-2012 (Ruggles et al. 2013). Nonparametric fit shows NadarayaWatson regression, bandwidth 0.1, fit to unlogged data, corresponding to Figure 7. A 95\% confidence interval is in gray.

supra-local effects are not among those considered most important in the literature (e.g. Fernández 2011).

Likewise, the exogeneity assumption is reasonable to first order. It would require an exotic model to posit that immigrants seek out places to settle based on reducing their own negative externality on natives. This would require knowing that in some cities immigrants cause inherently greater harm to natives' productivity, and immigrants choose the cities that they settle in so as to deliberately reduce this harm to natives. We are not aware of evidence that migrants choose their settlement patterns by this criterion.

We therefore test whether there are detectable differences in TFP between very highimmigration and very low-immigration portions of the United States. It is known that across United States cities, increases in migrant fraction are associated with increases in 
average earnings (Lewis and Peri 2015, p. 671). But there has been little investigation of high immigrant stocks.

Figure 8 shows a nonparametric regression of average earned income on foreign-born fraction, across local areas of the United States. The geographic divisions are 1,185 censusdefined 'Public Use Microdata Areas' or PUMAs, which contain more than 20,000 observations each for the American Community Survey pooled 2008-2012 sample. Collectively they cover the entire country, not only metropolitan areas.

The slope of the relationship is slightly positive from $0 \%$ immigrants to $30 \%$ immigrants, congruent with the several studies reviewed by Lewis and Peri (2015) showing positive overall productivity effects from local-area immigration at observed levels. The slope turns modestly negative at higher levels of immigrant concentration. Areas at the extreme of high immigrant concentration exhibit somewhat lower earned income: an immigrant share of $70 \%$ is associated with about $10 \%$ lower average earnings than areas with very low immigrant shares.

Figure 8 also superimposes the $c=0.5$ curve from Figure 7. (It is slightly distorted because the vertical scale of Figure 8 is logarithmic.) This comparison suggests that 0.5 represents a conservatively high upper bound on the magnitude of any true congestion effects. The left part of the curve is notably conservative because the model assumes no productivity enhancement from migrants at all, while the true relationship is positive below $30 \%$ immigrant stock. The right part of the curve is likewise conservative because the true relationship does not exhibit sufficient nonlinearity to fall below the $c=0.5$ curve at any point.

\section{Implications for dynamically efficient migration}

The range of plausible parameter values in the previous section suggests a corresponding range for the optimal migration rate. Table 1 shows that for a variety of different poor countries, assimilation $a$ lies in the range 0.026 and 0.128 , and transmission $\tau$ in the range 0.157 to 0.497 . Figure 8 suggests that congestion $c<0.5$. We can therefore superimpose 
Figure 9: Parameter estimates and optimal migration rates

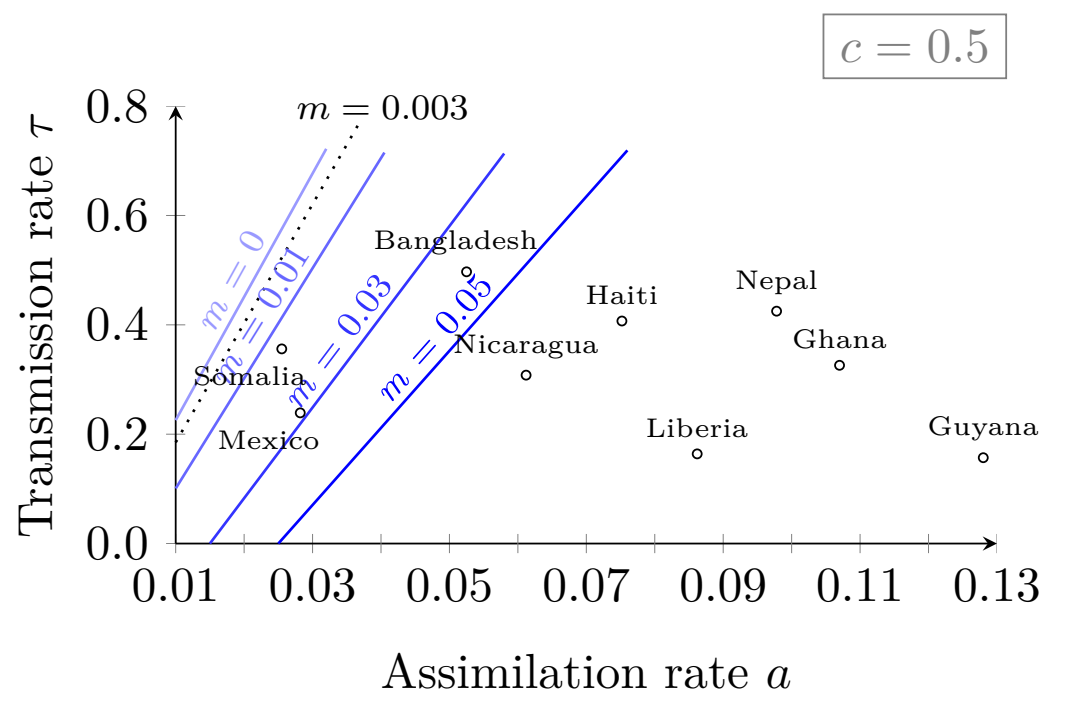

the estimates for assimilation and transmission on the graph of optimal migration rates for $c=0.5$ in Figure 3. This is shown in Figure 9.

In Figure 9, we do not find any parameter estimates that would support current the current migration rate $(m=0.003)$ as globally efficient. For all of the parameter estimates, corresponding rates of optimal migration are at least several times current levels, and in many cases far higher. This is because sufficiently little home-country productivity 'comes with' migrants, their initial productivity deficit erodes sufficiently quickly, and congestion is moderate in accordance with the data analyzed above.

This suggests that, while the Epidemiological Case for efficient migration restrictions is a theoretical possibility, it may be regarded as a conjecture with little empirical relevance for the foreseeable future. Of course, rates of transmission, assimilation, and congestion could change as migration proceeds. But Figure 9 makes it clear that they would need to change dramatically for today's migration rates to become globally optimal at some point. For that to happen, assimilation rates would need to fall to small fractions of their current values, and/or transmission and congestion would need to double. Such large changes would be necessary that changes could likely be detected long before they rendered a given migration rate suboptimal. 
We have made a number of assumptions that tend to keep the calibrated estimates of efficient migration conservatively low:

- No productivity gains in destination countries. The model here assumes that the exclusive productivity effect of immigrants in the destination country is to reduce it. This ignores the literature reviewed above, which finds important effects of migrants on trade, investment, technology, institutions, and norms that can raise TFP. A large literature has tested for total factor productivity effects of immigration at observed levels, finding those effects to be generally positive and substantial in a range of settings (reviewed by Lewis and Peri 2015, Table 10.2).

- No capital adjustment. The efficiency gains to international migration are enhanced by the fact that when the marginal product of labor falls, capital investment adjusts and compensates with a lag (Kennan 2013). In the model here, this never occurs.

- No value assigned to the steady-state gain once marginal product of labor is equalized. That is, the net present value of the static gain from migration, continuing from time $T$ to $\infty$, is not included in the condition for dynamically efficient migration.

- No replacement by children. The estimates of earnings assimilation from census data are for only for the foreign-born themselves, who are assumed to remain infinitely in the labor force. In reality, they are replaced by their children raised in the destination country - partially replaced within roughly 20-30 years as their children join the labor force, and fully replaced within 40-50 years as the immigrants retire. These children would on average exhibit more productivity-assimilation than their parents. The assimilation rate of the 'dynastic worker' in the model would therefore proceed at a higher rate than the empirical estimates of a in the previous section.

- 'Bad TFP' flows from poor to rich, but 'good TFP' does not flow from rich to poor. The model assumes that migration spreads low TFP to rich countries, but do not spread high TFP from rich to poor countries. That is, the model ignores a literature finding that migrants cause technology transfer back to developing countries (Kerr 2008); immigrants stimulate foreign direct investment by the destination country in the origin country (Javorcik et al. 2011); migrants who study in democratic countries transmit democratic norms back to the countries they come from (Spilimbergo 2009); 
and migrants may transfer low-fertility norms back to their countries of origin (Beine et al. 2013). All of these could raise home-country TFP, affecting the global gains to migration, but are omitted.

- The poorest and the richest weigh equally in social welfare. The efficient migration condition is blind to who receives the gains and losses counted there. In reality, the recipients of the TFP cost are relatively rich, while the recipients of the migration gains start out relatively poor. Atkinson (1970) or other social welfare weights that overweight income gains to the poorest would result in a higher value for migration. This is complicated by the fact that, at some point after migration, the initially poor take their place as the rich. The model omits these issues.

- High congestion. The congestion rate assumed in the calibration, 0.5, is conservatively low in U.S. locality data (Figure 8). Relaxing any of these strong assumptions would tend to result in higher estimates of the dynamically optimal migration rate.

\section{Conclusion}

The new case for efficiency-enhancing restrictions on labor mobility turns out to be an efficiency case against most existing restrictions on labor mobility. The new "epidemiological" argument against "open borders" relies on hypothetical deleterious impacts on productivity in the host country from "too many" migrants from low productivity countries. But the current situation for labor mobility is not open borders or anything remotely approaching open borders. The case against open borders is like the case against "free trade" being made in India in the late 1980s when India had both widespread licensing restrictions on nearly all imports and the highest tariffs in the world.

One can accept a theoretical case against open borders but still make the economic case that substantial reductions in existing barriers to labor mobility are potential Paretoimproving, and greatly so. Alternatively, even if there are arguments against open borders, marginal relaxations of barriers to labor mobility are still the highest potential impact reform for improving world material well-being. 
Our main analytical point is simple. The new conceptual case against open borders is that the flow of migration should be limited because the stock of something related to migration is too high. But to use the stock of the foreign born as the proxy to justify current restrictions on migration is unjustified in three senses.

First, this assumes that (a) migrants bring large fractions of their economic productivity with them, which is unsupported by evidence; or (b) that the restricting country is near the threshold in which the cumulative impact of migration would being to reduce economic productivity — which has yet to be demonstrated for any country or region. Moreover, no country or region appears to be at or over the threshold and most countries/regions have migration much lower than the highest migration penetration countries/regions. Thus most countries are not yet in the position of being able to justify restrictions on migration due to these threshold impacts.

Second, a non-linear impact on economic productivity of the stock of the foreign born implicitly assumes zero assimilation over time of migrants not matter at what age they came to the host country. That is, suppose a posited causal mechanism is that some of the foreign born come from countries with low average "trust", and that "trust" contributes (in general, on average) to the maintenance of market supporting institutions. Hence an increase in the foreign-born leads to a lower average level of "trust" which, over some time horizon, deteriorates economic productivity. But if migrants move toward the host country values, dispositions, attitudes and beliefs that sustain high economic productivity institutions (which does not require assimilation in other senses, such as homogenization of religion or identity) then the conceptually relevant measure is the "stock of the economicproductivity-institution-reducing population," what we term $\phi$. Our analysis suggests that with empirically plausible rates of "assimilation" in this narrow sense, there can be a large flow and stock of foreign born without substantially diminishing the global efficiency gains from reduced migration barriers.

Third, any case for restrictions on migration based on economic productivity would have to be well targeted. Such restrictions would need to be differentiated not against "foreign born" or even against countries but - to be justified as appropriate instruments for the 
target of efficiency - against people with specific beliefs/values/attitudes or, as a secondbest, against evidence of such. For example, assuming that since Indians come from a poor country those that migrate must come with productivity-reducing economic beliefs is too far-fetched to even entertain. Indians are the highest or second highest household income ethnicity in nearly all English speaking OECD countries (Chakravorty et al. 2016).

The efficiency cases against or for migration restrictions do not pretend that voters form their immigration preferences according to their consequences for economic efficiency. At least part of political support for migration restrictions seems to arise from dislike of the "other" and resent people not "like" them in some way (e.g. same race, religion, ethnicity, food preference, language) or, more positively, feel restrictions on migration are needed to maintain a particular "way of life" or "culture" or political structures and outcomes with inherent rather than instrumental value (Hainmueller and Hopkins 2014). Economists since John Stuart Mill have disallowed direct utility externalities as a basis for welfaremotivated restrictions on free choice. Enforcing maximization of a social welfare function that included sadists' taste for others' suffering, or prudes' distaste for others' salacious reading, would require a radically illiberal order (Sen 1970; Hausman and McPherson 1993, p. 690). On the other hand, if migration barriers are deemed necessary to preserve a "way of life" of inherent value, it would need to be clarified why similar reasoning would not have obstructed the Industrial Revolution, the entry of women into the labor force, and the abolition of serfdom - all of which greatly altered an existing "way of life".

The precise extent of additional migration under a more liberal regime remains a subject for further research. The first forays into this area are wanting: It is unserious to posit that the global labor market is currently at full spatial equilibrium based on data regarding state-to-state movement within a rich country, and it is premature to cast global predictions of migration behavior based on a contingent valuation survey. Initial estimates using broadly-coded changes in migration restrictions suggest that policy barriers are major determinants of migration flows (Ortega and Peri 2013). Such estimates are complicated by the difficulty of quantifying migration policy, and by the fact that multilateral liberalization can have different effects than bilateral liberalization (Bertoli and Fernández-Huertas 2013). Contradictory recent evidence suggests that, in different 
settings, poor migrants are highly willing to migrate (Bryan et al. 2014) or surprisingly unwilling to migrate (Beam et al. 2016). One promising research direction may be to use much more advanced survey methods, such as those advocated by Manski (2004), to elicit more reliable estimates of migration behavior in hypothetical scenarios.

The global efficiency effects of reduced migration barriers suggest another important line of future research: institutional mechanisms to turn potential Pareto improvements into realized Pareto Improvements. These are the subject of little-explored proposals for migration taxes by Becker and Becker (1997) and Freeman (2006), and proposals for immigration quota auctions by Orrenius and Zavodny (2010), Peri (2012b), and Fernández-Huertas and Rapoport (2014). National governments control migration restrictions, and characterizing the global efficiency effects of migration restrictions is just the first step in the overdue literature on the efficiency effects of migration.

\section{References}

Aleksynska, Mariya and Giovanni Peri, "Isolating the network effect of immigrants on trade," The World Economy, 2014, 37 (3), 434-455.

Alesina, Alberto, Johann Harnoss, and Hillel Rapoport, "Birthplace diversity and economic prosperity," NBER Working Paper 18699, National Bureau of Economic Research 2013.

_ , Paola Giuliano, and Nathan Nunn, "On the Origins of Gender Roles: Women and the Plough," The Quarterly Journal of Economics, 2013, 128 (2), 469-530.

Algan, Yann and Pierre Cahuc, "Trust and growth," Annual Review of Economics, 2013, 5 (1), 521-549.

_ and _, "Trust, Growth, and Well-Being: New Evidence and Policy Implications," in Philippe Aghion and Steven N. Durlauf, eds., Handbook of Economic Growth, Vol. 2, Amsterdam: Elsevier, 2014, pp. 49-120.

Arrow, Kenneth, Robert Solow, Paul R Portney, Edward E Leamer, Roy Radner, and Howard Schuman, "Report of the NOAA Panel on Contingent Valuation," Federal Register, 1993, 58 (10), 4602-4614.

Ashenfelter, Orley C., "Comparing Real Wage Rates: Presidential Address," American Economic Review, 2012, 102 (2), 617-642.

Atkinson, Anthony B, "On the measurement of inequality," Journal of Economic Theory, 1970, 2 (3), 244-263.

Bahar, Dany and Hillel Rapoport, "Migration, knowledge diffusion and the comparative advantage of nations," Working Paper, Harvard University 2015. 
Bandiera, Oriana, Imran Rasul, and Martina Viarengo, "The Making of Modern America: Migratory Flows in the Age of Mass Migration," Journal of Development Economics, 2013, 102, $23-47$.

Banerjee, Abhijit, Esther Duflo, Nathanael Goldberg, Dean Karlan, Robert Osei, William Parienté, Jeremy Shapiro, Bram Thuysbaert, and Christopher Udry, "A multifaceted program causes lasting progress for the very poor: Evidence from six countries," Science, 2015, 348 (6236), 1260799.

Bateman, Ian, Alistair Munro, Bruce Rhodes, Chris Starmer, and Robert Sugden, "A Test of the Theory of Reference-Dependent Preferences," Quarterly Journal of Economics, 1997, $112(2), 479-505$.

Batina, Raymond G and Toshihiro Ihori, Public Goods: Theories and Evidence, New York: Springer Science \& Business Media, 2005.

Beam, Emily, David McKenzie, and Dean Yang, "Unilateral facilitation does not raise international labor migration from the Philippines," Economic Development and Cultural Change, 2016, 64 (2), 323-368.

Becker, Gary and Guity Nashat Becker, The economics of life: From baseball to affirmative action to immigration, how real-world issues affect our everyday life, New York: McGraw Hill Professional, 1997.

Beine, Michel, Frédéric Docquier, and Maurice Schiff, "International migration, transfer of norms and home country fertility," Canadian Journal of Economics, 2013, 46 (4), 1406-1430.

Benhabib, Jess and Boyan Jovanovic, "Optimal Migration: A World Perspective," International Economic Review, 2012, 53 (2), 321-348.

Bertoli, Simone and Jesús Fernández-Huertas, "Multilateral resistance to migration," Journal of Development Economics, 2013, 102, 79-100.

_ and _, "The size of the cliff at the border," Regional Science and Urban Economics, 2015, $51,1-6$.

_, _, and Francesc Ortega, "Crossing the border: Self-selection, earnings and individual migration decisions," Journal of Development Economics, 2013, 101, 75-91.

Beugelsdijk, Sjoerd and Robbert Karel Jozef Maseland, Culture in Economics: History, Methodological Reflections and Contemporary Applications, Cambridge: Cambridge University Press, 2011.

Bhagwati, Jagdish N, "Incentives and disincentives: International migration," Review of World Economics, 1984, 120 (4), 678-701.

_, "Why Borjas fails to persuade," in Alan V Deardorff and Robert Mitchell Stern, eds., Social Dimensions of US Trade Policies, Ann Arbor: University of Michigan Press, 2000, pp. 87-94.

Bodvarsson, Örn B and Hendrik van den Berg, The Economics of Immigration: Theory and Policy, 2nd ed., New York: Springer, 2013.

Borjas, George J, "The Labor Demand Curve Is Downward Sloping: Reexamining The Impact Of Immigration On The Labor Market," The Quarterly Journal of Economics, 2003, 118 (4), $1335-1374$.

_, Immigration Economics, Cambridge: Harvard University Press, 2014.

_., "Immigration and globalization: A review essay," Journal of Economic Literature, 2015, 53 
(4), 961-974.

_ , Stephen G Bronars, and Stephen J Trejo, "Assimilation and the Earnings of Young Internal Migrants," Review of Economics and Statistics, 1992, 74 (1), 170-75.

Bradford, Scott, "The global welfare and poverty effects of rich nation immigration barriers," Working Paper, Dept. of Economics, Brigham Young University 2015.

Bryan, Gharad, Shyamal Chowdhury, and Ahmed Mushfiq Mobarak, "Underinvestment in a Profitable Technology: The Case of Seasonal Migration in Bangladesh," Econometrica, 2014, 82 (5), 1671-1748.

Butler, Jeffrey, Paola Giuliano, and Luigi Guiso, "The right amount of trust," Journal of the European Economic Association, 2016, forthcoming.

Camerer, Colin, Linda Babcock, George Loewenstein, and Richard Thaler, "Labor Supply of New York City Cabdrivers: One Day at a Time," Quarterly Journal of Economics, 1997, $112(2), 407-441$.

Caplan, Bryan, "Trillion Dollar Bills on the Sidewalk: The Borjas Critique," Econlog weblog, July 162014 .

Card, David, "Is the new immigration really so bad?," Economic Journal, 2005, 115 (507), F300-F323.

_ , "Immigration and Inequality," American Economic Review, 2009, 99 (2), 1-21.

- and Giovanni Peri, "Immigration Economics: A Review," Journal of Economic Literature, 2016, forthcoming.

Caselli, Francesco and James Feyrer, "The Marginal Product of Capital," Quarterly Journal of Economics, 2007, 122 (2), 535-568.

Chakravorty, S., D. Kapur, and N. Singh, The Other One Percent: Indians in America, Cambridge: Harvard University Press, 2016.

Chiquiar, Daniel and Gordon H Hanson, "International Migration, Self-Selection, and the Distribution of Wages: Evidence from Mexico and the United States," Journal of Political Economy, 2005, 113 (2), 239-281.

Clark, JR, Robert Lawson, Alex Nowrasteh, Benjamin Powell, and Ryan Murphy, "Does immigration impact institutions?," Public Choice, 2014, 163 (3-4), 321-335.

Clemens, Michael A, "Economics and Emigration: Trillion-Dollar Bills on the Sidewalk?," Journal of Economic Perspectives, 2011, 25 (3), 83-106.

_ , "Why do programmers earn more in Houston than Hyderabad? Evidence from randomized processing of US visas," American Economic Review, 2013, 103 (3), 198-202.

_, "A case against taxes and quotas on high-skill emigration," Journal of Globalization and Development, 2014, 5 (1), 1-39.

_, Claudio E. Montenegro, and Lant Pritchett, "The Place Premium: Wage Differences for Identical Workers Across the US Border," Working Paper, Harvard Kennedy School of Government 2009.

Collier, Paul, Exodus: How Migration Is Changing Our World, Oxford: Oxford University Press, 2013.

Cortés, Patricia and José Tessada, "Low-Skilled Immigration and the Labor Supply of Highly 
Skilled Women," American Economic Journal: Applied Economics, 2011, 3 (3), 88-123.

Dell, Melissa, "The persistent effects of Peru's mining mita," Econometrica, 2010, 78 (6), 18631903.

DHS, Malawi Demographic and Health Survey, 2010, Calverton: National Population Council, 2011.

di Giovanni, Julian, Andrei A Levchenko, and Francesc Ortega, "A global view of crossborder migration," Journal of the European Economic Association, 2015, 13 (1), 168-202.

Diamond, Peter A and Jerry A Hausman, "Contingent Valuation: Is Some Number Better than No Number?," Journal of Economic Perspectives, 1994, 8 (4), 45-64.

Docquier, Frédéric, Joël Machado, and Khalid Sekkat, "Efficiency gains from liberalizing labor mobility," Scandinavian journal of economics, 2015, 117 (2), 303-346.

Dohmen, Thomas, Armin Falk, David Huffman, and Uwe Sunde, "The intergenerational transmission of risk and trust attitudes," Review of Economic Studies, 2012, 79 (2), 645-677.

Esipova, N., J. Ray, and A. Pugliese, Gallup World Poll: The Many Faces of Global Migration, Geneva: IOM, International Organization for Migration, 2011.

Fernández-Huertas, Jesús and Hillel Rapoport, "Tradable immigration quotas," Journal of Public Economics, 2014, 115, 94-108.

Fernández, Raquel, "Does culture matter?," in Jess Benhabib, Matthew O. Jackson, and Alberto Bisin, eds., Handbook of Social Economics, Vol. 1A, Amsterdam: North-Holland, 2011, pp. 481510 .

Fisman, Raymond and Edward Miguel, "Corruption, Norms, and Legal Enforcement: Evidence from Diplomatic Parking Tickets," Journal of Political Economy, 2007, 115 (6), 10201048.

Freeman, Richard B, "People Flows in Globalization," Journal of Economic Perspectives, 2006, $20(2), 145-170$.

Gollin, Douglas, "Getting Income Shares Right," Journal of Political Economy, 2002, 110 (2), 458-474.

Grogger, Jeffrey and Gordon H Hanson, "Income maximization and the selection and sorting of international migrants," Journal of Development Economics, 2011, 95 (1), 42-57.

Guerriero, Marta, "The Labour Share of Income around the World. Evidence from a Panel Dataset," Development Economics and Public Policy Working Paper 32. University of Manchester 2012 .

Guiso, Luigi, Paola Sapienza, and Luigi Zingales, "Does Culture Affect Economic Outcomes?," Journal of Economic Perspectives, 2006, 20 (2), 23-48.

Hainmueller, Jens and Daniel J Hopkins, "Public Attitudes Toward Immigration," Annual Review of Political Science, 2014, 17, 225-249.

Hall, Robert E and Charles I Jones, "Why do Some Countries Produce So Much More Output Per Worker than Others?," Quarterly Journal of Economics, 1999, 114 (1), 83-116.

_ and _ , "Why do some countries produce so much more output per worker than others?," NBER Working Paper 6564. National Bureau of Economic Research 1999.

Hamilton, Bob and John Whalley, "Efficiency and distributional implications of global re- 
strictions on labour mobility: Calculations and policy implications," Journal of Development Economics, 1984, 14 (1), 61-75.

Hatton, T.J. and J.G. Williamson, The Age of Mass Migration: Causes and economic impact, New York: Oxford University Press, 1998.

Hausman, Daniel M and Michael S McPherson, "Taking Ethics Seriously: Economics and Contemporary Moral Philosophy," Journal of Economic Literature, 1993, 31 (2), 671-731.

Hausman, Jerry, "Contingent Valuation: From Dubious to Hopeless," Journal of Economic Perspectives, 2012, 26 (4), 43-56.

Helliwell, John F and Robert D Putnam, "Economic Growth and Social Capital in Italy," Eastern Economic Journal, 1995, 21 (3), 295-307.

Hidalgo, César A and Ricardo Hausmann, "The building blocks of economic complexity," Proceedings of the National Academy of Sciences, 2009, 106 (26), 10570-10575.

Hsieh, Chang-Tai and Peter J Klenow, "Development Accounting," American Economic Journal: Macroeconomics, 2010, 2 (1), 207-23.

Iregui, Ana María, "Efficiency Gains from the Elimination of Global Restrictions on Labour Mobility," in George J. Borjas and Jeff Crisp, eds., Poverty, International Migration and Asylum, New York: Palgrave Macmillan, 2005, pp. 211-238.

Isaac, Julius, Economics of Migration, London: Routledge, Trench, Trubner \& Co. Ltd., 1947.

Javorcik, Beata S, Çağlar Özden, Mariana Spatareanu, and Cristina Neagu, "Migrant networks and foreign direct investment," Journal of Development Economics, 2011, 94 (2), $231-241$.

Jensen, Robert, "The (perceived) returns to education and the demand for schooling," Quarterly Journal of Economics, 2010, 125 (2), 515-548.

Jones, Charles I, "The Facts of Economic Growth," in John B. Taylor and Harald Uhlig, eds., Handbook of Macroeconomics, Vol. 2, forthcoming, 2016.

Kahneman, Daniel and Jack L Knetsch, "Valuing public goods: the purchase of moral satisfaction," Journal of environmental economics and management, 1992, 22 (1), 57-70.

Kennan, John, "Open borders," Review of Economic Dynamics, 2013, 16 (2), L1-L13.

- and James R Walker, "The effect of expected income on individual migration decisions," Econometrica, 2011, 79 (1), 211-251.

Kerr, William R, "Ethnic scientific communities and international technology diffusion," Review of Economics and Statistics, 2008, 90 (3), 518-537.

- and William F Lincoln, "The Supply Side of Innovation: H-1B Visa Reforms and US Ethnic Invention," Journal of Labor Economics, 2010, 28 (3), 473-508.

Klein, Paul and Gustavo J Ventura, "TFP differences and the aggregate effects of labor mobility in the long run," The BE Journal of Macroeconomics, 2007, 7 (1).

- and Gustavo Ventura, "Productivity differences and the dynamic effects of labor movements," Journal of Monetary Economics, 2009, 56 (8), 1059-1073.

Köszegi, Botond and Matthew Rabin, "A Model of Reference-Dependent Preferences," Quarterly Journal of Economics, 2006, 121 (4), 1133-1165.

Kremer, Michael, "Globalization of labor markets and inequality," in "Brookings Trade Forum," 
Vol. 1 Brookings Institution Press 2006, pp. 211-228.

LaLonde, Robert J, Robert $\mathbf{H}$ Topel et al., "Immigrants in the American Labor Market: Quality, Assimilation, and Distributional Effects," American Economic Review, 1991, 81 (2), 297-302.

Lawson, Robert A and Saurav Roychoudhury, "Do Travel Visa Requirements impede Tourist Travel?," Journal of Economics and Finance, 2016, forthcoming.

Lewis, Ethan and Giovanni Peri, "Immigration and the Economy of Cities and Regions," in Gilles Duranton, J. Vernon Henderson, and William C. Strange, eds., Handbook of Regional and Urban Economics, Vol. 5, Amsterdam: Elsevier, 2015, pp. 625-685.

Lubotsky, Darren, "Chutes or Ladders? A Longitudinal Analysis of Immigrant Earnings," Journal of Political Economy, 2007, 115 (5), 820-867.

Manski, Charles F, "Measuring Expectations," Econometrica, 2004, 72 (5), 1329-1376.

Mbaye, Linguère Mously, "Barcelona or die': Understanding illegal migration from Senegal," IZA Journal of Migration, 2014, 3 (1), 1-19.

McKenzie, D., S. Stillman, and J. Gibson, "How Important is Selection? Experimental vs. Non-Experimental Measures of the Income Gains from Migration," Journal of the European Economic Association, 2010, 8 (4), 913-945.

Milanovic, Branko, "Global Income Inequality in Numbers: in History and Now," Global Policy, 2013, 4 (2), 198-208.

_ , "Global Inequality of Opportunity: How Much of Our Income Is Determined by Where We Live?," Review of Economics and Statistics, 2015, 97 (2), 452-460.

Mishra, Prachi, "Emigration and wages in source countries: A survey of the empirical literature," in Robert E. B. Lucas, ed., International Handbook on Migration and Economic Development, Cheltenham: Edward Elgar, 2014, pp. 241-266.

Moses, Jonathon W and Bjørn Letnes, "The economic costs to international labor restrictions: Revisiting the empirical discussion," World Development, 2004, 32 (10), 1609-1626.

_ and _ , "If People Were Money: Estimating the Gains and Scope of Free Migration," in George J. Borjas and Jeff Crisp, eds., Poverty, International Migration and Asylum, New York: Palgrave Macmillan, 2005, pp. 188-210.

Müller, Daniel, Benno Torgler, and Eric M Uslaner, "A Comment on 'Inherited Trust and Growth'," Economics Bulletin, 2012, 32 (2), 1481-1488.

Nunn, Nathan, "The Long-term Effects of Africa's Slave Trades," Quarterly Journal of Economics, 2008, 123 (1), 139-176.

- and Leonard Wantchekon, "The Slave Trade and the Origins of Mistrust in Africa," American Economic Review, 2011, 101 (7), 3221-52.

OECD, "The fiscal impact of immigration in OECD countries," in "International Migration Outlook 2013," Paris: OECD, 2013, pp. 125-189.

Orrenius, Pia M and Madeline Zavodny, Beside the Golden Door: U.S. immigration reform in a new era of globalization, Washington, DC: AEI Press, 2010.

Ortega, Francesc and Giovanni Peri, "The effect of income and immigration policies on international migration," Migration Studies, 2013, 1 (1), 47-74. 
Ottaviano, Gianmarco IP and Giovanni Peri, "Rethinking the effect of immigration on wages," Journal of the European Economic Association, 2012, 10 (1), 152-197.

Peri, Giovanni, "The effect of immigration on productivity: Evidence from US states," Review of Economics and Statistics, 2012, 94 (1), 348-358.

_ , "Rationalizing US Immigration Policy: Reforms for Simplicity, Fairness, and Economic Growth," Technical Report 2012.

Pritchett, Lant, Let their people come: Breaking the gridlock on global labor mobility, Washington, DC: Center for Global Development, 2006.

_ , "The Cliff at the Border," in Michael Spence and Ravi Kanbur, eds., Equity and Growth in a Globalizing World, 2010, pp. 263-286.

_ and Rebekah Smith, "Is there a Goldilocks Solution?: 'Just Right' Promotion of Labor Mobility in a Post-2015 World," 2016.

Putterman, Louis and David N Weil, "Post-1500 Population Flows and The Long-Run Determinants of Economic Growth and Inequality," Quarterly Journal of Economics, 2010, 125 (4), 1627-1682.

Rauch, James E, "Networks versus markets in international trade," Journal of International Economics, 1999, 48 (1), 7-35.

Ruggles, Steven, J. Trent Alexander, Katie Genadek, Ronald Goeken, Matthew B. Schroeder, and Matthew Sobek, "American Community Survey 5-year, 2008-2012," Integrated Public Use Microdata Series: Version 5.0 [Machine-readable database], Minneapolis: University of Minnesota 2013.

Seabright, Paul, The Company of Strangers: A Natural History of Economic Life, Princeton: Princeton University Press, 2004.

Sen, Amartya, "The impossibility of a Paretian liberal," Journal of Political Economy, 1970, 78 (1), 152-157.

Spilimbergo, Antonio, "Democracy and Foreign Education," American Economic Review, 2009, 99 (1), 528-543.

Stillman, Steven, John Gibson, David McKenzie, and Halahingano Rohorua, "Miserable migrants? Natural experiment evidence on international migration and objective and subjective well-being," World Development, 2015, 65, 79-93.

Taylor, Alan M and Jeffrey G Williamson, "Convergence in the age of mass migration," European Review of Economic History, 1997, 1 (1), 27-63.

van der Mensbrugghe, Dominique and David Roland-Holst, "Global Economic Prospects for Increasing Developing Country Migration into Developed Countries," United Nations Development Programme Human Development Research Paper 2009/50, Human Development Report Office (HDRO), United Nations Development Programme (UNDP) 2009.

Walmsley, Terrie L and L Alan Winters, "Relaxing the restrictions on the temporary movement of natural persons: A simulation analysis," Journal of Economic Integration, 2005, 20 (4), $688-726$.

Wolf, Martin, "The benefits of migration are questionable: Cosmopolitanism is incompatible with our organisation into territorial jurisdictions," Financial Times, 2015, September 29.

Wydick, Bruce, Paul Glewwe, and Laine Rutledge, "Does international child sponsorship 
work? A six-country study of impacts on adult life outcomes," Journal of Political Economy, 2013, 121 (2), 393-436. 